\title{
Comparative Pathogenesis, Genomics and Phylogeography of Mousepox
}

\author{
Carla Mavian ${ }^{1,+} \mathbb{D}$, Alberto López-Bueno ${ }^{1}$, Rocío Martín ${ }^{1}$, Andreas Nitsche ${ }^{2}$ (D) and Antonio Alcamí ${ }^{1, *(D)}$ \\ 1 Centro de Biología Molecular Severo Ochoa, Consejo Superior de Investigaciones Científicas, Campus de \\ Cantoblanco, Universidad Autónoma de Madrid, Nicolás Cabrera 1, 28049 Madrid, Spain; \\ cmavian@ufl.edu (C.M.); alopezbueno@cbm.csic.es (A.L.-B.); mrmartin@cbm.csic.es (R.M.) \\ 2 Centre for Biological Threats and Special Pathogens, Highly Pathogenic Viruses (ZBS1), Robert Koch Institute, \\ 13353 Berlin, Germany; NitscheA@rki.de \\ * Correspondence: aalcami@cbm.csic.es \\ + Current Address: Immunology and Laboratory Medicine, Department of Pathology, Emerging Pathogens \\ Institute, College of Medicine, University of Florida, Gainesville, FL 32610, USA.
}

check for updates

Citation: Mavian, C.; López-Bueno, A.; Martín, R.; Nitsche, A.; Alcamí, A. Comparative Pathogenesis, Genomics and Phylogeography of Mousepox. Viruses 2021, 13, 1146. https:/ / doi.org/10.3390/v13061146

Academic Editors: Jônatas Abrahão and Hermann Meyer

Received: 29 April 2021

Accepted: 10 June 2021

Published: 15 June 2021

Publisher's Note: MDPI stays neutral with regard to jurisdictional claims in published maps and institutional affiliations.

Copyright: (c) 2021 by the authors. Licensee MDPI, Basel, Switzerland. This article is an open access article distributed under the terms and conditions of the Creative Commons Attribution (CC BY) license (https:// creativecommons.org/licenses/by/ $4.0 /)$.

\begin{abstract}
Ectromelia virus (ECTV), the causative agent of mousepox, has threatened laboratory mouse colonies worldwide for almost a century. Mousepox has been valuable for the understanding of poxvirus pathogenesis and immune evasion. Here, we have monitored in parallel the pathogenesis of nine ECTVs in BALB/cJ mice and report the full-length genome sequence of eight novel ECTV isolates or strains, including the first ECTV isolated from a field mouse, ECTV-MouKre. This approach allowed us to identify several genes, absent in strains attenuated through serial passages in culture, that may play a role in virulence and a set of putative genes that may be involved in enhancing viral growth in vitro. We identified a putative strong inhibitor of the host inflammatory response in ECTV-MouKre, an isolate that did not cause local foot swelling and developed a moderate virulence. Most of the ECTVs, except ECTV-Hampstead, encode a truncated version of the P4c protein that impairs the recruitment of virions into the A-type inclusion bodies, and our data suggest that P4c may play a role in viral dissemination and transmission. This is the first comprehensive report that sheds light into the phylogenetic and geographic relationship of the worldwide outbreak dynamics for the ECTV species.
\end{abstract}

Keywords: mousepox; poxvirus pathogenesis; genome sequence; virulence; A-type inclusion bodies

\section{Introduction}

Orthopoxviruses have played an important role in human history: variola virus (VARV), the causative agent of smallpox, was one of the most lethal human pathogens; vaccinia virus (VACV) and cowpox virus (CPXV) were key for the discovery of vaccination [1-4]. Today, 40 years after the eradication of smallpox, VARV still represents a threat as a bioterrorist weapon, and CPXV and monkeypox virus are the main cause of zoonotic poxvirus infections [5-7]. The orthopoxvirus ectromelia virus (ECTV) is the causative agent of mousepox, an acute exanthematous disease of mice that resembles smallpox and was used as a model for studying orthopoxvirus infections [8-10]. Mousepox was a serious threat to laboratory mouse colonies in the past [11-14], but outbreaks of mousepox in laboratory mouse colonies have been eliminated thanks to strict surveillance and improvements in animal house facilities with pathogen contention racks, filters and disinfections [11]. The first ECTV outbreak was reported in 1930 in the National Institute for Medical Research in Hampstead (London, UK) and was caused by the ECTV-Hampstead (ECTV-H) isolate (Table 1). The disease was named "infectious ectromelia" because of the characteristic foot amputation observed in mice that recovered from infection [8]. Sixty passages in chorioalantoic membranes (CAMs) of ECTV-H resulted in the attenuated strain ECTV-Hampstead Egg (ECTV-HE) that shows a considerable reduction in virulence in outbred mice [15], and 
the same origin was proposed for the attenuated strain ECTV-Mill Hill (ECTV-MH) [16]. After this first case, numerous outbreaks were reported in animal facilities across Europe and in 1946 the highly virulent ECTV-Moscow (ECTV-M) was isolated from an outbreak in Moscow [17]. ECTV-H and ECTV-M were used by F. Fenner in early studies to characterize mousepox pathogenesis [15,17-23]. Since then, numerous ECTV outbreaks were registered in Europe: in 1976 there were outbreaks in mouse colonies in Munich and Nuremberg, Germany, where ECTV-MP1 (ECTV-M1) and ECTV-MP4 (ECTV-M4) were isolated, respectively, and later in 1994 the isolate ECTV-MP5 (ECTV-M5) was responsible from an outbreak in Wien, Austria [24,25]. In 1986 and 1988 two outbreaks in Warsaw, Poland, were firstly described as ECTV isolates, but their genome sequencing demonstrated that they corresponded to VACV $[26,27]$. In the 1950s, mousepox outbreaks were also described in China and Japan, where another laboratory outbreak was registered in Ishibashi and the causative agent was the isolate ECTV-Ishibashi (ECTV-I), which was attenuated by more than 30 passages in cell culture [28]. A study of sera from 150 wild mice around Melbourne did not detect exposure to ECTV, suggesting the absence of this virus in the Australian continent [29]. In North America, ECTV was not enzootic, and the first official ECTV outbreak was described in Yale University in 1953 [30]. Occasional outbreaks were registered until 1979-1980 when the ECTV-NIH79 isolate caused a series of devastating outbreaks that led the National Institute of Health to create a surveillance committee that prohibited the introduction of ECTV in USA [31,32]. The last outbreaks in this continent were reported in 1995 and 1999 [33,34]. The isolate ECTV-Naval (ECTV-N), responsible for the outbreak of 1995, was isolated at the US Naval Medical Research Institute in Bethesda (Maryland, USA) and derived from a commercial serum imported from China that caused a lethal disease in BALB/cJ mice $[34,35]$. The ECTV outbreak of 1999 at the Weill Medical College of Cornell University in New York (USA) was caused by ECTV-Cornell, which was found to be genetically identical to ECTV-N $[34,36]$. The source of this virus was also linked to commercial mouse serum imported from China, consistent with the genomes of ECTV-N and ECTV-C sharing more than $99 \%$ of nucleotide (nt) sequence identity with erythomelalgia-related poxvirus (ERPV), an ECTV isolated in China [34,37].

The mouse is the known natural host of ECTV, aside from one report in the silver fox [38], and it has been proposed that populations of wild mice in Europe can represent the reservoir of ECTV as the virus can transmit from wild mice to laboratory-mouse colonies [12,39]. However, to our knowledge, there is only one report describing the isolation of ECTV from a wild mouse, but this identification was not further confirmed by genetic analyses [39]. Phylogenetic analysis of the highly conserved central region of poxvirus genomes identified ECTV in a unique branch of the orthopoxvirus as the most distant species within this genus [40]. The genome of ECTV encodes a highly specialized array of proteins that interact with the mouse immune system and play a critical role in viral pathogenesis and host defense $[34,37,41]$. The availability of a mouse model for ECTV has facilitated the in vivo characterization of many of these genes by following a knockingdown strategy [42-46]. The restricted number of ECTV isolates with full-length genome sequences available, currently only ECTV-M, ECTV-N, and ERPV [34,37,41], has limited the identification of genes involved in virulence by correlating gene-content and virulence from different virus isolates, a strategy successfully followed with other poxviruses [47-49]. Despite the relevance of ECTV outbreaks in laboratory mouse colonies and the importance of mousepox in classical studies of viral pathogenesis, there are no studies addressing the genomic diversity of ECTV isolates.

In this study, we present a comparative analysis of the pathogenesis in BALB/cJ mice and the full-length genome sequence of a collection of ECTV isolates from worldwide laboratory outbreaks and ECTV strains attenuated after serial passage in cell culture or CAMs. We also report the first characterization of an ECTV isolated from a wild mouse in 2008 in the region of Krefeld (Germany), named ECTV-MouKre (ECTV-MK). Comparison of the tissue culture growth and virulence in susceptible mice of the ECTV isolates, linked to their genomic sequence, has identified putative virulence determinants 
and new immunomodulatory molecules encoded by ECTV. Differences in the ability of the ECTV isolates to recruit virions to A-type inclusion (ATI) bodies has allowed us to address the role of ATI bodies in ECTV transmission. Finally, by calibrating a molecular clock and applying Bayesian ancestral reconstruction, this study provides phylogenetic support to trace connections between the historical outbreaks of ECTV in laboratory mouse colonies.

Table 1. ECTV isolates and strains used in this study.

\begin{tabular}{|c|c|c|c|c|c|}
\hline Isolate & Location of Collection & Date of Collection & Origin & Plaque Isolation & Reference \\
\hline $\begin{array}{l}\text { ECTV-Hampstead } \\
\text { (ECTV-H) }\end{array}$ & $\begin{array}{l}\text { National Institute for Medical } \\
\text { Research, London, United } \\
\text { Kingdom }\end{array}$ & 1930 & $\begin{array}{l}\text { Mouse colony } \\
\text { outbreak }\end{array}$ & no & [8] \\
\hline $\begin{array}{l}\text { ECTV-Moscow } \\
\text { (ECTV-M) }\end{array}$ & Moscow, Russia & 1946 & $\begin{array}{l}\text { Mouse colony } \\
\text { outbreak and cell } \\
\text { culture passages }\end{array}$ & yes & [17] \\
\hline $\begin{array}{l}\text { ECTV-Hamsptead } \\
\text { Egg(ECTV-HE) }\end{array}$ & - & 1949 & $\begin{array}{l}\text { ECTV-H passed in } \\
\text { chorioalantoic } \\
\text { membranes }\end{array}$ & no & [15] \\
\hline $\begin{array}{l}\text { ECTV-Mill Hill } \\
\text { (ECTV-MH) }\end{array}$ & - & 1959 & $\begin{array}{l}\text { ECTV-H passed in } \\
\text { chorioalantoic } \\
\text { membranes }\end{array}$ & no & [16] \\
\hline $\begin{array}{l}\text { ECTV-Ishibashi } \\
\text { (ECTV-I) }\end{array}$ & Ishibashi, Japan & 1966 & $\begin{array}{l}\text { Mouse colony } \\
\text { outbreak and cell } \\
\text { culture passages }\end{array}$ & yes & [28] \\
\hline $\begin{array}{l}\text { ECTV-MP1 } \\
\text { (ECTV-M1) }\end{array}$ & Munich, Germany & 1976 & $\begin{array}{l}\text { Mouse colony } \\
\text { outbreak }\end{array}$ & no & [24] \\
\hline $\begin{array}{l}\text { ECTV-MP4 } \\
(\text { ECTV-M4) }\end{array}$ & Nuremberg, Germany & 1976 & $\begin{array}{l}\text { Mouse colony } \\
\text { outbreak }\end{array}$ & no & [25] \\
\hline $\begin{array}{l}\text { ECTV-MP5 } \\
\text { (ECTV-M5) }\end{array}$ & Wien, Austria & 1994 & $\begin{array}{l}\text { Mouse colony } \\
\text { outbreak }\end{array}$ & no & [25] \\
\hline $\begin{array}{l}\text { ECTV-Naval } \\
(\text { ECTV-N) }\end{array}$ & $\begin{array}{l}\text { US Naval Medical Research } \\
\text { Institute in Bethesda }\end{array}$ & 1995 & $\begin{array}{l}\text { Mouse colony } \\
\text { outbreak and cell } \\
\text { culture passages }\end{array}$ & yes & [35] \\
\hline $\begin{array}{c}\text { ECTV-MouKre } \\
\text { (ECTV-MK) }\end{array}$ & Krefeld, Germany & 2008 & Wildlife & no & $\begin{array}{l}\text { This } \\
\text { study }\end{array}$ \\
\hline
\end{tabular}

\section{Materials and Methods}

\subsection{Cells and Viruses}

Monkey kidney BS-C-1 cells (ATCC: CCL-26) were used for virus amplification and preparation of semi-purified viral stocks as described [34]. ECTV-H [8] and ECTV-MH [16] (original stocks from K. Dumbell) were supplied by J. Williamson (St. Mary's Hospital, Imperial College School of Medicine, London, United Kingdom); ECTV-HE was provided by A. Mullbacher (John Curtin School of Medical Research, Australian National University, Canberra, Australia) [15]; ECTV-I was provided by Y. Ichihashi (Faculty of Medicine, Niigata University, Niigata, Japan) [28]; ECTV-M1 [24], ECTV-M4 and ECTV-M5 [25] were supplied by H. Meyer (Institute of Microbiology, Federal Armed Forces Medical Academy, Munich, Germany); ECTV-MK was isolated in 2008 from wild mice in the region of Krefeld, Germany, by A. Nitsche (The Robert Koch Institute, Berlin, Germany); ECTV-M (ECTVMoscow-3-P2) is a plaque-purified isolate provided by R. M. L. Buller (School of Medicine, Saint Louis University) [17,41]; ECTV-N is a plaque-purified isolate [34] derived from the original stock of the Naval Medical Research Institute outbreak (Bethesda, MD, USA) provided by R. M. L. Buller [35]. A list of the viruses used in the study is given in Table 1. 
Virus titers were determined by plaque assays on BS-C-1 cell monolayers grown. Briefly, cells were infected for $2 \mathrm{~h}$ with different virus doses in Dulbecco's Modified Eagle Medium DMEM 2.5\% heat-inactivated fetal bovine serum, and after $2 \mathrm{~h}$ the medium was replaced by a semi-solid medium consisting of carboxymethylcellulose (1500-3000 centipoise; Sigma-Aldrich, Saint Louis, MO, USA) at $0.15 \%$ weight/volume $(w / v)$ and carboxymethylcellulose (50-200 centipoise; Sigma-Aldrich, Saint Louis, MO, USA) at $0.15 \%(w / v)$ in Dulbecco's Modified Eagle Medium DMEM 2.5\% heat-inactivates fetal bovine serum. Cell monolayers were stained 5 days later with $2 \%$ crystal violet and $2 \%$ formaldehyde to identify virus plaques.

One-step growth curve experiments were assessed on BS-C-1 cells infected at a multiplicity of infection of 3.5-10 plaque-forming unit ( $\mathrm{pfu}$ ) per cell ( $\mathrm{pfu} / \mathrm{cell}$ ) and viral titers were determined at $0,3,7,11$ and $24 \mathrm{~h}$ post-infection (hpi) as described [34].

\subsection{In Vivo Experiments}

Groups of 6-7 weeks old female BALB/cJ or DBA/2 mice (Charles River Laboratories) were anesthetized using isofluorane and infected subcutaneously (s. c.) in the left hind footpad with different doses of ECTV or phosphate buffer saline (PBS) as control. Signs of illness and body weight were monitored daily for 19 days post-infection (dpi). Mice were housed in biosafety level 3 ventilated racks (Allentown) with free access to food and water and $12 \mathrm{~h}$ light $/ 12 \mathrm{~h}$ dark cycle.

To assess viral dissemination, mice were infected with 10 pfu of ECTV-M or ECTV-H and sacrificed to obtain popliteal lymph nodes, spleen and liver at 3 dpi, and spleen, liver and lung at 5 and $7 \mathrm{dpi}$. Transmission of the virus was analyzed in groups of mice infected with $10^{3} \mathrm{pfu}$ of ECTV-M or ECTV-H. Two of these infected mice were transferred to a cage containing four uninfected mice (exposed group) at 2, 4 and 7 dpi to assess early (group 1), intermediate (group 2) or late (group 3) transmission, respectively. Three days post-exposure (dpe), the infected mice were removed from the cage. Exposed mice were sacrificed $7 \mathrm{dpe}$, and spleen and liver viral load were determined by plaque assay as indicator of viral transmission. Organs were PBS-washed and homogenized in PBS to $10 \%(w / v)$ with a $5 \mathrm{~mm}$ steel sphere using the TissueLyser II (Qiagen) with $1 \mathrm{~min}$ at $30 \mathrm{~Hz}$ pulses twice for the liver, four times for the lung and five times for the spleen. Statistical significance was inferred applying a non-parametric two tail Mann-Whitney test using GraphPad Prism 9 (GraphPad Software, San Diego, CA, USA).

\subsection{Electron Microscopy}

BS-C-1 cells infected at a multiplicity of infection of $10 \mathrm{pfu} /$ cell or spleen samples from infected BALB/cJ mice were fixed with $4 \%$ paraformaldehyde and $2 \%$ glutaraldehyde in $1 \times$ PBS for $60 \mathrm{~min}$ at room temperature. Postfixation was carried out with $1 \% \mathrm{OsO}_{4}$ and $1 \% \mathrm{~K}_{3} \mathrm{Fe}(\mathrm{CN})_{6}$ in distilled $\mathrm{H}_{2} \mathrm{O}$ at $4{ }^{\circ} \mathrm{C}$ for $60 \mathrm{~min}$, and subsequently fixed again with $0.15 \%$ tannic acid in PBS. Fixed samples were incubated with $2 \%$ uranyl acetate for $1 \mathrm{~h}$, dehydrated with absolute ethanol, flat-embedded in Epon resin (Epoxi, TAAB812, TAAB Laboratories, Berkshire, England) overnight, replaced once and finally polymerized at $60{ }^{\circ} \mathrm{C}$ for $48 \mathrm{~h}$. Images were captured under a JEM1010 electronic microscope coupled to a TemCam-F416 (4 K × $4 \mathrm{~K}$ ) camera (TVIPS, Gauting, Germany) under a magnification of $10,000 \times$. Only cells that were clearly infected, as harboring virions in the cell, were quantified. One hundred cells per ECTV isolate from different sections were captured and analyzed to quantify the number of cells presenting an ATI bodies positive phenotype.

\subsection{Genome Sequencing and Assembly}

Two $\mu \mathrm{g}$ of viral DNA, obtained from semi-purified viral stocks as described [34], were used for the construction of a library using the GS-FLX Titanium system (454 Life Sciences, Roche, Branford, CT, USA) and sequenced with a FLX Genome Sequencer in the Scientific Park of Madrid, Spain. Reads were de novo assembled and also mapped to ECTV-M or ECTV-N reference genomes with Newbler 2.5.3 (Roche Diagnostics, Branford, CT, USA). 
For Illumina sequencing, five $\mu \mathrm{g}$ of viral DNA of ECTV-M was used to construct a TruSeq library and reads obtained with a Genome Analyzer IIx in the Scientific Park of Madrid, Spain. These Illumina reads were mapped to ECTV-M genome (AF012825.2) as reference using Bowtie2 with default parameters (http:/ /bowtie-bio.sourceforge.net/bowtie2/manual. shtml; Version 2.1.0) (Table 2). A PCR amplification of the region containing the Direct Repeat III (DRIII) region of ECTV-MK was carried out as described [27]. The product was analyzed in a $2 \%$ agarose gel with a $100 \mathrm{bp}$ ladder marker (Invitrogen) considering the most intense band for the estimation of the number of repeats.

Table 2. Summary of data obtained by next-generation sequencing of the ECTV genomes.

\begin{tabular}{cccccc}
\hline ECTV & Reads & $\begin{array}{c}\text { Average Size } \\
\text { (bp) }\end{array}$ & $\begin{array}{c}\text { Mapped } \\
\text { Reads }\end{array}$ & Coverage (x) & $\begin{array}{c}\text { Genome } \\
\text { Size (bp) }\end{array}$ \\
\hline ECTV-H & 96,434 & 365 & $\begin{array}{c}69,503 \\
(72.0 \%)\end{array}$ & 122 & 206,771 \\
ECTV-HE & 240,573 & 370 & $\begin{array}{c}218,157 \\
(90.7 \%)\end{array}$ & 390 & 206,745 \\
ECTV-I & 25,360 & 396 & $\begin{array}{c}17,411 \\
(68.6 \%)\end{array}$ & 33 & 207,479 \\
ECTV-MH & 120,182 & 387 & $\begin{array}{c}117,070 \\
(97.4 \%)\end{array}$ & 218 & 207,108 \\
ECTV-M1 & 79,430 & 396 & $\begin{array}{c}69,600 \\
(87.6 \%)\end{array}$ & 133 & 206,842 \\
ECTV-M4 & 77,287 & 385 & $\begin{array}{c}71,527 \\
(92.5 \%)\end{array}$ & 132 & 207,700 \\
ECTV-M5 & 46,469 & 393 & $\begin{array}{c}41,334 \\
(88.9 \%)\end{array}$ & 78 & 207,348 \\
ECTV-MK & 112,670 & 302 & $\begin{array}{c}57,779 \\
(51.3 \%)\end{array}$ & 83 & 209,592 \\
ECTV-M & $22,391,099$ & 100 & $\begin{array}{c}10,490,202 \\
(46.85 \%)\end{array}$ & 5001 & 209,771 \\
\hline
\end{tabular}

a All strains were sequenced with 454-Roche technology except the ECTV-M that was sequenced with Illumina technology.

\subsection{Genome Annotation, Analysis and Comparison}

The genomes were annotated using Artemis (Wellcome Trust Sanger Institute, United Kingdom) as described [34,50]. Genes and pseudogenes were named with a three-letter acronym for each ECTV strain (the first two letters stand for ECTV and the third for the isolate/strain) and a consecutive number from the left to the right region of the genome. Pseudogenes are indicated with a P after the number. Genome identity percentage and nucleotide differences among genomes were obtained by full-length genome alignment using Geneious Pro 6.1 (Biomatters, Auckland, New Zealand). The graphical representation of the genomic differences (smooth plot) among the genomes of the new ECTV isolates/strains, and the published genomes of ECTV-N (KJ563295), ERPV (JQ410350.1) and CPXV-BR (AF482758.2), was obtained by BLASTz alignment using the mVista software (http:/ / genome.lbl.gov/vista/index.shtml, University of California, Berkeley, California, USA) and ECTV-M (NC_004105.1) as reference. Dot plot analysis of ECTV-H and ECTV-HE genomes was performed using the JDotter program (http:/ / athena.bioc.uvic.ca/virology-ca-tools/jdotter/, University of Victoria, Victoria, Canada). The proteins encoded by each gene from all the ECTV strains were individually aligned with Clustaw2 (http:/ /www.ebi.ac.uk/Tools/msa/clustalw2/, EMBL-EBI in Hinxton, Cambridge, UK).

\subsection{Bayesian Phylogeography Analysis}

The presence of temporal signal $\left(R^{2}=0.74\right.$, correlation coefficient $\left.=0.86\right)$ was assessed using TempEst v1.7 (University of Edinburgh, Edinburgh, UK) [51] (Figure S1) and a maximum likelihood tree with best-fit HKY model chosen according to Bayesian Infor- 
mation Criteria (BIC) implemented in the IQ-TREE v1.6.12 (University of Vienna, Vienna, Austria) [52] and based on the single nt polymorphisms in the $64 \mathrm{kbp}$ conserved central region of the genome (from 74,472 to 138,348 nt of the genome of ECTV-M) extracted from the whole genome alignment using MEGA5 [53,54]. The phylogeny includes previously published genome sequences of ECTV-M, ECTV-N, and ERPV. Bayesian ancestral state (phylogeography) and tree reconstruction was performed in BEAST v1.10.4 (University of Edinburgh, Edinburgh, UK, and University of California, Los Angeles, CA, USA) [55], using a HKY substitution model with empirical base frequencies and gamma distribution of site-specific rate heterogeneity, a constant size demographic prior, a strict molecular clock, ascertainment bias correction (ABC) model to take into account that only variable sites are being used [56], a discrete trait, asymmetric transition (migration) model, and Bayesian stochastic search variable selection (BSSVS) models. The strength of evidence against the null hypothesis $\left(H_{0}\right)$ was evaluated via MLE comparison with the more complex model $\left(H_{A}\right)$, referred to as the Bayes Factor $(\mathrm{BF})$, wherein $\ln \mathrm{BF}<2$ indicates no evidence against $H_{0} ; 2-6$ - weak evidence; 6-10-evidence; 10-20-strong evidence, and >20 indicates very strong evidence [57]. Markov chain Monte Carlo (MCMC) samplers were run for 1 billion generations to achieve proper mixing of the Markov chain evaluated by calculating the Effective Sampling Size (ESS) of the parameter estimates with Tracer v1.7 (University of Edinburgh, Edinburgh, UK, and University of California, Los Angeles, CA, USA). ESS > 250 (after 10\% a burn-in) were considered robust. The posterior distribution of the sampled trees was summarized within the maximum clade credibility (MCC) tree using TreeAnnotator and specifying a burn-in of $10 \%$ and median node heights. The MCC tree was visualized in FigTree v1.4.2 (University of Edinburgh, Edinburgh, UK), and nodes with $\mathrm{PP} \geq 0.99$ were considered to be evidence of statistically significant phylogenetic relationships. Xml file is available upon request.

\section{Results}

\subsection{Different Virulence Patterns and Foot Swelling Elicited by ECTV Isolates and Strains in} $B A L B / c J$ Mice

ECTV can infect all laboratory mouse strains but has different severities depending on the mouse strain and the route of infection [58]. C57BL/6 and AKR strains are resistant to severe disease by s. c. infection in the footpad, whereas A, BALB/cJ, DBA, and C3H are susceptible to severe disease by this route $[59,60]$. The virulence of several ECTV strains/isolates has been studied in diverse mouse models $[4,13,34,61]$. However, due to the diversity of mouse genetic backgrounds used in previous studies, it is difficult to reach clear conclusions about their comparative pathogenesis. We have analyzed the virulence of nine ECTV isolates and strains in susceptible BALB/cJ mice infected s. c. in the footpad, the classical model of mousepox. The set of ECTV isolates tested in this experiment included the virulent isolates ECTV-M [41] and ECTV-H [8], three virus isolates (ECTV-M1, ECTV-M4 and ECTV-M5) from laboratory outbreaks in Central Europe [24] and a natural ECTV isolated from a wild mouse in Germany (ECTV-MK). We also included ECTVs attenuated after serial passage in cell culture (ECTV-I) [28] or CAMs (ECTV-HE and ECTV-MH) $[15,16]$.

Unlike the highly virulent phenotype of ECTV-M with a lethal dose 50 (LD ${ }_{50}$ ) value bellow 1 pfu (10), mice infected with ECTV-H did not show a dose-dependent mortality and morbidity in two independent experiments despite following a dose-dependent behavior in foot swelling, with similar high degree of swelling occurring at all doses with certain delay, and signs of illness such as hunch back, absence of mobility and conjunctivitis since 4-6 dpi (Figure 1, Table S1). Thus, for the ECTV-H isolate, it was not possible to estimate a $\mathrm{LD}_{50}$ in the BALB/cJ mouse model. Similar experiments performed in DBA/2 mice showed a dose-dependent mortality for ECTV-M and ECTV-N, but not for ECTV-H, and confirmed the attenuated phenotype of ECTV-I (Table S2). 


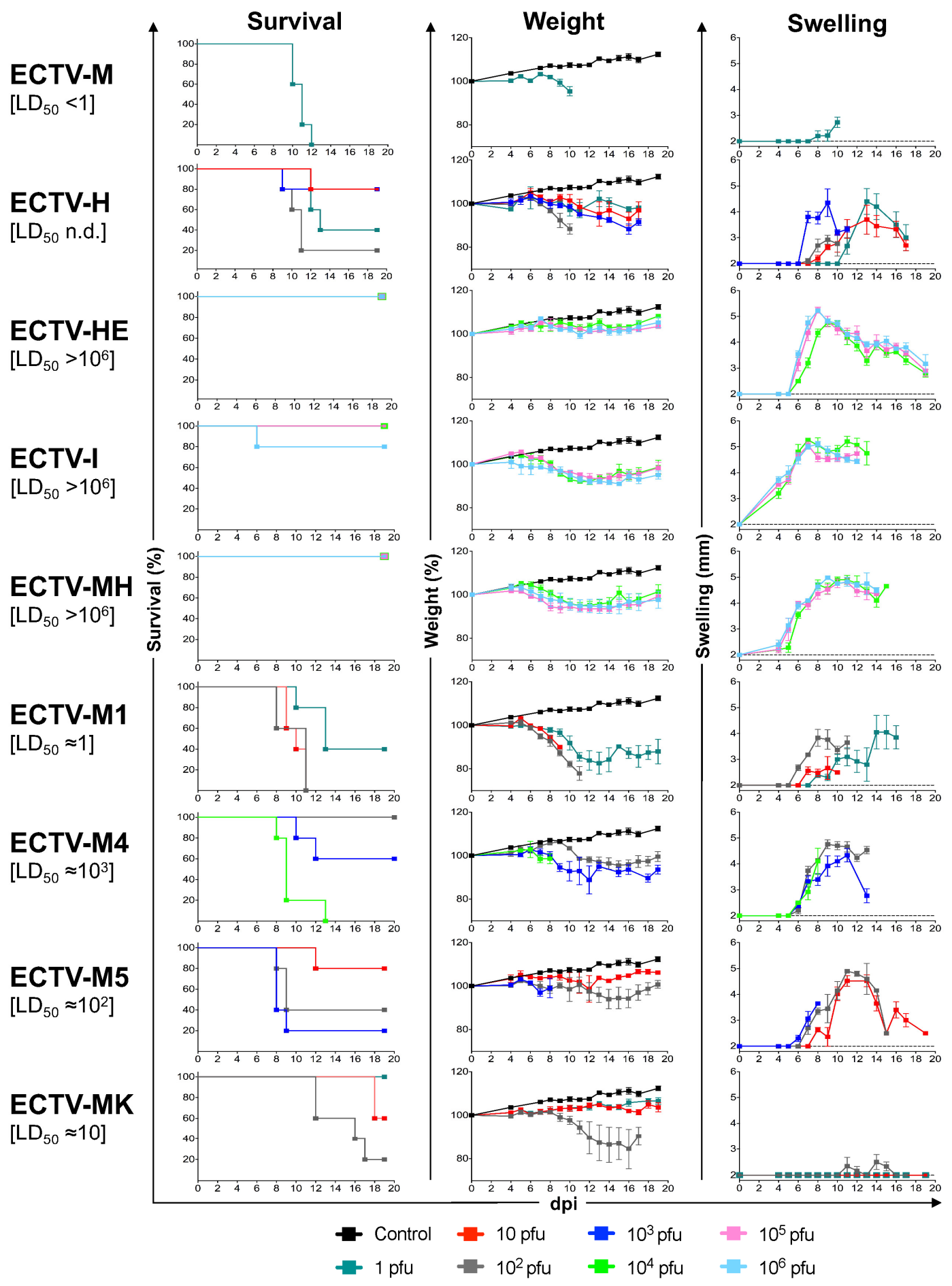

Figure 1. Virulence of ECTV isolates and strains in susceptible mice. Groups of five female BALB/cJ mice were infected s. c. in the footpad with the indicated ECTV and monitored during $19 \mathrm{~d}$. The percentage of survival and weight, with respect to uninfected mice, and swelling of the inoculated foot are shown from left to right.Mice were infected with various doses: 1 pfu (dark green line in ECTV-M, ECTV-H, ECTV-M1, and ECTV-MK), 10 pfu (red line in ECTV-H, ECTV-M1, ECTV-M5, and ECTV-MK), $10^{2}$ pfu (gray line in ECTV-H, ECTV-M1, ECTV-M4, ECTV-M5, and ECTV-MK), $10^{3}$ pfu (dark blue line in ECTV-H, ECTV-M4, and ECTV-M5), $10^{4}$ pfu (light green line in ECTV-HE, ECTV-I, ECTV-MH, and ECTV-M4), $10^{5}$ pfu (pink line in ECTV-HE, ECTV-I, and ECTV-MH) or $10^{6}$ pfu (light blue line in ECTV-HE, ECTV-I, and ECTV-MH). The black line represents control animals. Mean \pm SD are represented. M, ECTV-M; H, ECTV-H; HE, ECTV-HE; I, ECTV-I; MH, ECTV-MH; M1, ECTV-M1; M4, ECTV-M4; M5, ECTV-M5; MK, ECTV-MK. The results shown with ECTV-MP1, ECTV-MP4, ECTV-MP5, ECTV-MK and ECTV-H are representative of two experiments. 
ECTV-I, ECTV-HE and ECTV-MH were highly attenuated with estimated $\mathrm{LD}_{50}>10^{6} \mathrm{pfu}$, as previously described in other mouse strains $[4,16]$ (Figure 1, Table S1). The unique death of a mouse infected with $10^{6} \mathrm{pfu}$ of ECTV-I is unlikely to be related to the viral infection since it occurred earlier than the first death of mice infected with virulent strains. Mice infected with ECTV-HE did not show weight loss but instead showed symptoms of illness, including loss of hair in the ocular zone and ulcerative rash in the tail, between 6-14 dpi followed by a slow recovery; whereas mice infected with several doses of ECTV-MH and ECTV-I showed by 15 dpi a small but reproducible weight loss. ECTV-M infection caused a rapid appearance of illness ranging from 8-11 dpi, just before the death of the animals and including ruffled fur, hunched posture and severe ulcerative rash in the tail. In contrast, mice infected with ECTV-MH and ECTV-I showed signs of illness for an extended period of time, ranging from 6 to 19 dpi. Unlike ECTV-M, ECTV-MH and ECTV-I also caused a severe ulcerative rash in ocular area with consequent conjunctivitis-like reaction and loss of fur around the eyes. Moreover, the highly attenuated ECTV-HE, ECTV-MH and ECTV-I strains elicited a severe foot swelling from 4-6 dpi suggestive of immune system activation. This inflammation evolved with the natural amputation of the inoculated foot in all mice infected with ECTV-I at all doses, with the exception of one mouse infected with $10^{4} \mathrm{pfu}$ that suffered an advanced state of necrosis. By contrast, only one mouse infected with $10^{6} \mathrm{pfu}$ of ECTV-MH lost the foot and all animals infected with ECTV-HE recovered from the foot swelling by the end of the experiment. Therefore, these three highly attenuated strains showed clear differences in the way that the local immune system resolves the exacerbated inflammation at the inoculation site.

ECTV-M1, ECTV-M4, ECTV-M5 and ECTV-MK exhibited intermediate estimated LD 50 values, with ECTV-M1 being the most virulent and ECTV-M4 the most attenuated isolate (Figure 1, Table S1). Inoculation of $10^{2}$ pfu of ECTV-M5 caused $60 \%$ mortality by $9-10$ dpi and the same doses caused 80\% mortality in ECTV-MK but a week later. Signs of illness were severe in all animals infected with these four ECTV strains, but weight loss was more pronounced in mice infected with ECTV-M1, the most virulent virus. ECTV-M1, ECTV-M4 and ECTV-M5 elicited a strong footpad swelling with values similar to those recorded for highly attenuated strains by 8 dpi (Figure 1, Table S1). Consistently, ECTV-M4, the most attenuated virus of the group, caused the same paw strangulation observed in mice infected with ECTV-I and ECTV-MH, without further amputation. Intriguingly, the virus isolated from a wild mouse (ECTV-MK) did not cause swelling of the foot at any time, even in mice infected with high doses.

\subsection{Only ECTV-H and ECTV-HE Produce ATI Bodies with Embedded Virions}

To gain insights into the differences observed in BALB/cJ pathogenesis, we first investigated the phenotype of the ECTV isolates and strains in cell culture. Both attenuated and virulent ECTVs efficiently produced viral plaques in BS-C-1 cells with the same morphology at 3-4 dpi, and exhibited similar growth curves in experiments limited to a one-step growth curve experiment (Figure 2A,B). Interestingly, ECTV-M1 and ECTV-M5 formed syncytia and produced the highest virus yield and fastest growth curves. These results ruled out possible viral replication or propagation impairments as the cause of the attenuated phenotype shown by some ECTVs in vivo. 

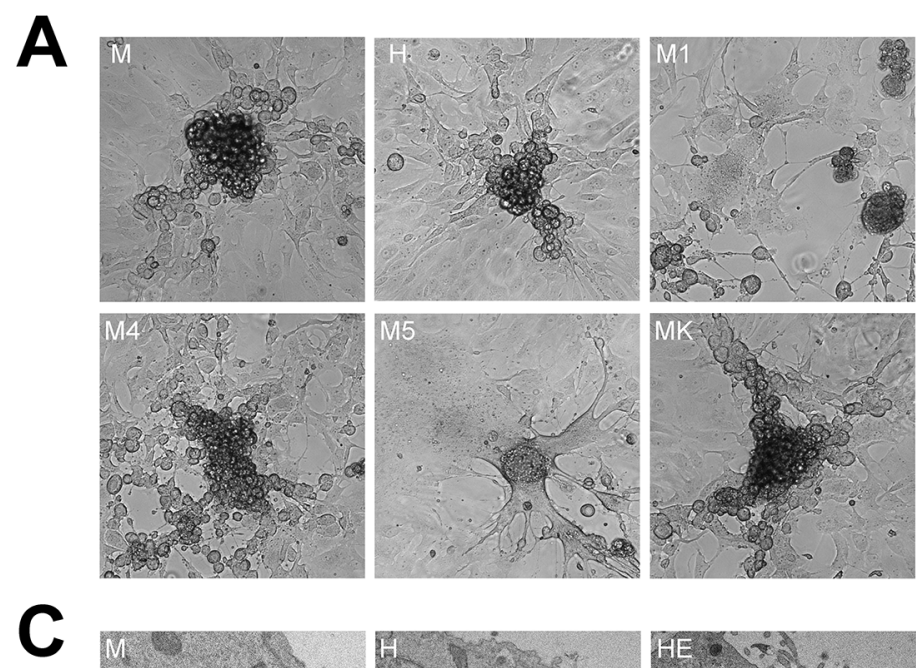

\section{B}
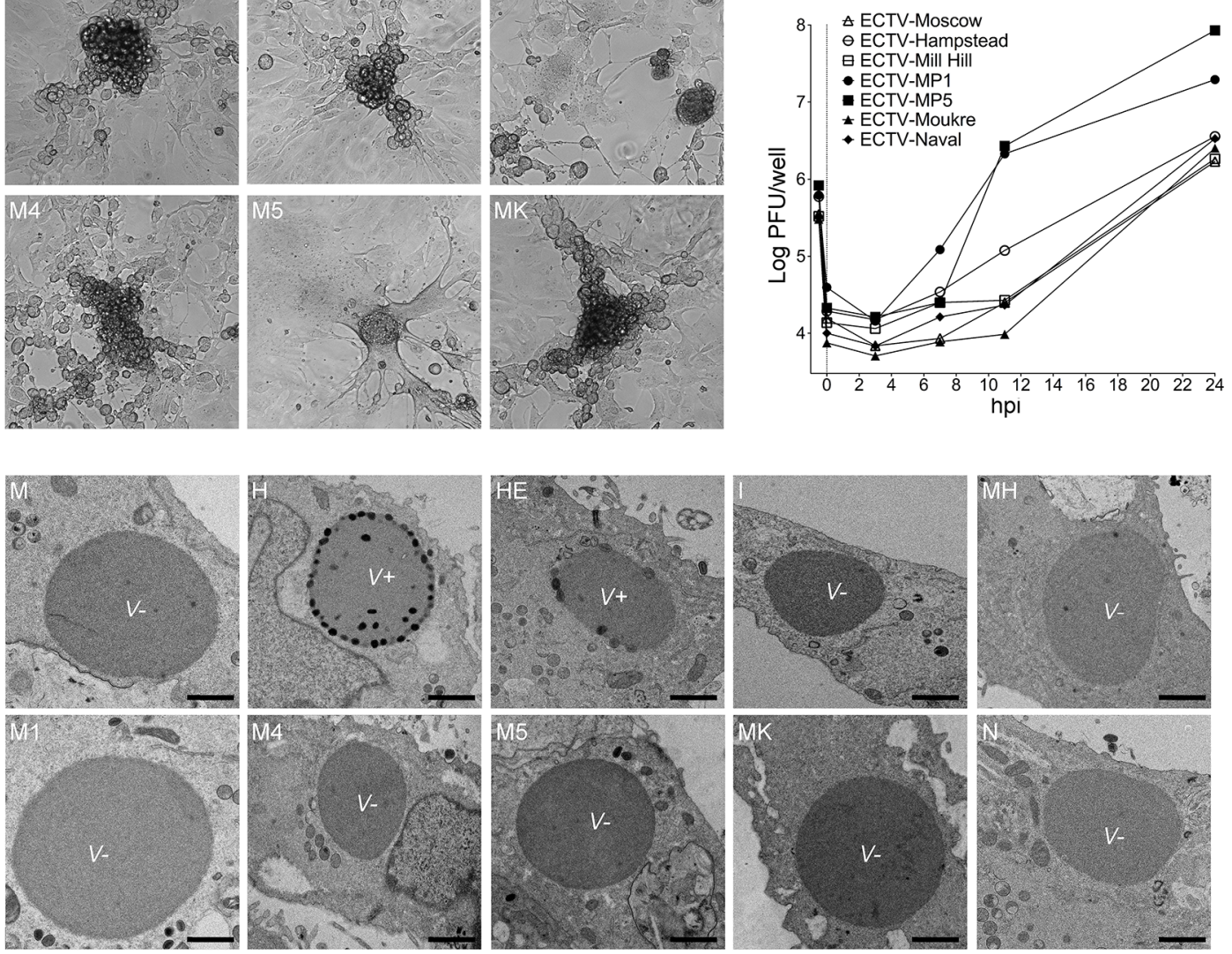

Figure 2. Replication of ECTV isolates and strains in tissue culture. (A) Representative micrographs of lysis plaque morphology formed by the indicated ECTV isolate/strain in BS-C-1 cells at 96 hpi were captured with a phase contrast microscope Leica DM IL LED (Leica Microsystems) at 400× magnification. (B) One-step growth curve experiment of ECTV infection. BS-C-1 cells were infected with 3.5-10 pfu/cell of the indicated ECTV isolate/strain and virus titers determined at different times after infection. The results are representative of two experiments and each point is the mean of two lysis plaque assay determinations. Virus titer is indicated in Log10. (C) Representative electron micrographs of ECTV-induced ATI bodies in BS-C-I cells at $24 \mathrm{hpi}$. The presence of virions in ATI bodies is indicated with $\mathrm{V}^{+}$and the absence of virions with $\mathrm{V}^{-}$. Bars: $400 \mathrm{~nm}$.

ECTV forms ATI bodies in infected cells and it has been reported that ECTV-H presents intracellular mature virions either embedded into or on the surface of ATI bodies [28,62]. We confirmed the presence of ATI bodies containing virions $\left(\mathrm{V}^{+}\right.$phenotype) in $90 \%$ of the BS-C-1 cells infected with ECTV-H and ECTV-HE by electron microscopy (Figure 2C). However, we found that this phenotype constitutes an exception within the ECTV isolates and strains tested as the other eight ECTVs, including ECTV-M and ECTV-N, formed ATI bodies with a $\mathrm{V}^{-}$phenotype, i.e., without virions either attached to or embedded into ATIs.

3.3. Genomic and Phylogeographic Analyses Unveil Two Major Clades within the ECTV Isolates and Strains

The full-length genome sequence of eight ECTVs was determined by using the 454Roche deep-sequencing technology (Table 2). The entire coding regions were de novo assembled into two contigs of 35 and $163 \mathrm{kbp}$ separated by the long and variable DRIII region [34]. The DRIII region of the ECTV-MK genome was PCR-amplified as previously described for the other ECTVs [34] and 63 repeats of $24 \mathrm{bp}$ were estimated for ECTV-MK (data not shown). The non-coding terminal regions DRI and DRII were not determined in this study. Consistently with the genome length reported for the three available ECTV genome sequences [34,37,41], the new eight ECTV genomes ranged from 204 to $208 \mathrm{kbp}$, 
and the sequence was determined with an average coverage between $33 \times$ and $390 \times$. Additionally, the genome of ECTV-M was re-sequenced by using the Illumina technology with an average coverage of $5001 \times$ (Table 2). The A+T content of $66.6-66.8 \%$ found in the ECTV genomes is characteristic of orthopoxviruses. The central region of the genome of the ECTV isolates and strains was highly conserved and mutations largely accumulated towards the ends of the genome, where the immunomodulatory and virulence genes are located (Figure 3A).

The maximum clade credibility (MCC) tree based on the alignment of $64 \mathrm{kbp}$ from the central region of the ECTV genome showed that ECTV isolates and strains group into two clades that we defined as European clade and Asian clade (Figure 3B). The first clade comprises the European isolates and strains ECTV-H, ECTV-HE, ECTV-M, ECTV$\mathrm{MH}, \mathrm{ECTV}-\mathrm{M} 1, \mathrm{ECTV}-\mathrm{M} 4, \mathrm{ECTV}-\mathrm{M} 5$ and ECTV-MK, and the Japanese isolate ECTV-I. In agreement with their geographic origin, ECTV-M1, ECTV-M4, ECTV-M5 and ECTVMK are closely related and form a subclade within the European clade that we named Central-European subclade. These isolates were independently isolated in Germany in 1976 in the cities of Munich (ECTV-M1) and Nunberg (ECTV-M4), in the region of Krefeld (Germany) in 2008 (ECTV-MK), and in Wien (Austria) in 1994 (ECTV-M5) [24,25]. The Asian clade includes ERPV and ECTV-N, whose relationship was previously described [34]. ECTV-H and ECTV-M are the most related ECTV genomes differing in only $30 \mathrm{nt}$ (Table 3). These $30 \mathrm{nt}$ found in ECTV-H are also conserved in the other ECTV genomes belonging to the European clade, suggesting that the European ECTV isolates and strains are more closely related to ECTV-H than to ECTV-M, the reference isolate for ECTV. The European and Asian clades diverged around 177 CE (95\% Higher Posterior Density interval [HPD] 772 BCE-877 CE). The time of the most common ancestor (tMRCA) of the Asian clade, composed by ERPV strain form China and ECTV-N from USA [34], is 1960 (95\% HPD 1943-1976).

Table 3. Number of nt differences among ECTV genomes.

\begin{tabular}{ccccccccc}
\hline & ECTV-M & ECTV-H & ECTV-I & ECTV-MH & ECTV-M1 & ECTV-M4 & ECTV-M5 & ECTV-MK \\
\hline ECTV-M & - & 30 & 167 & 361 & 148 & 186 & 362 & 589 \\
ECTV-H & 30 & - & 138 & 331 & 138 & 156 & 353 & 559 \\
ECTV-I & 167 & 138 & - & 437 & 258 & 274 & 473 & 689 \\
ECTV-MH & 361 & 331 & 437 & - & 352 & 348 & 531 & 732 \\
ECTV-M1 & 148 & 138 & 258 & 352 & - & 130 & 297 & 527 \\
ECTV-M4 & 186 & 156 & 274 & 348 & 130 & - & 363 & 565 \\
ECTV-M5 & 362 & 353 & 473 & 531 & 297 & 363 & - & 285 \\
ECTV-MK & 589 & 559 & 689 & 732 & 527 & 565 & 285 & - \\
\hline
\end{tabular}

The Bayesian phylogeographic analysis is in agreement with genomic information and the history of the outbreaks. Isolates belonging to the European clade find their origin in the United Kingdom, connected to the early outbreaks caused by ECTV-H (Figure 3B). The time when ECTV-H, progenitor of the European outbreaks, diverged from ECTV-MH, is also the tMRCA of the European clade: 1896 (95\% HPD 1866-1918). A clear unidirectional flow of ECTV from the United Kingdom to Germany, to Russia and to Japan was observed (Figure 3C, Table 4). The Central-European subclade emerged in 1942 (tMRCA 95\% HPD 1928-1956). Within this clade, the wild mouse isolate ECTV-MK diverged from ECTV-M5 in 1968 (tMRCA 95\% HPD 1956-1981), indicating that its ancestor emerged sometime between 1968 and 2008, the year of its first isolation. This analysis corroborates that infection of mouse colonies in Germany in the 1970s may have caused occasional spillover events of a virus closely related ECTV-MP5 into the wild mouse population in Germany, where the natural ECTV-MK isolate was found, and further raising the possibility of the existence of a wildlife reservoir of ECTV in Europe. Strong evidence of viral flow was also observed from Germany to Austria where ECTV-M5 was isolated [25], suggesting again that ECTV was or is circulating within a wildlife reservoir in Germany. The analysis draws a possible two- 
way connection between China and USA (Figure 3C, Table 4). However, it is conceivable to assume the movement of ECTV to be unidirectional, and specifically from China to USA $[34,37]$. Finally, this analysis does not provide clear information about evolution direction between European and Asian clades.

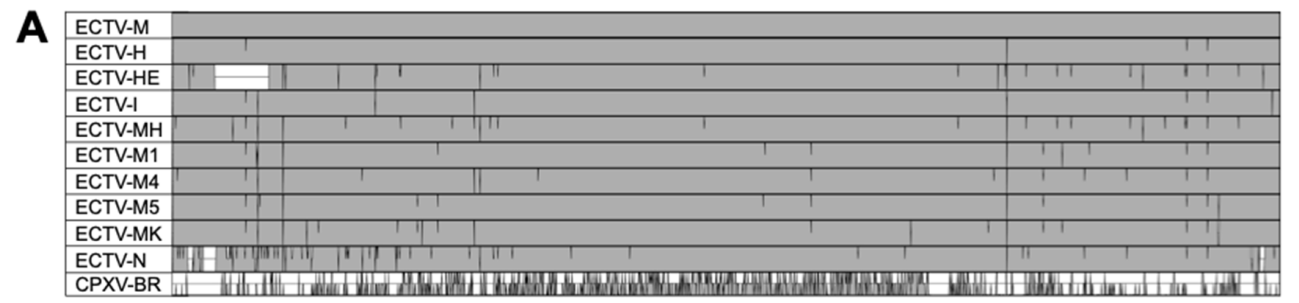

B

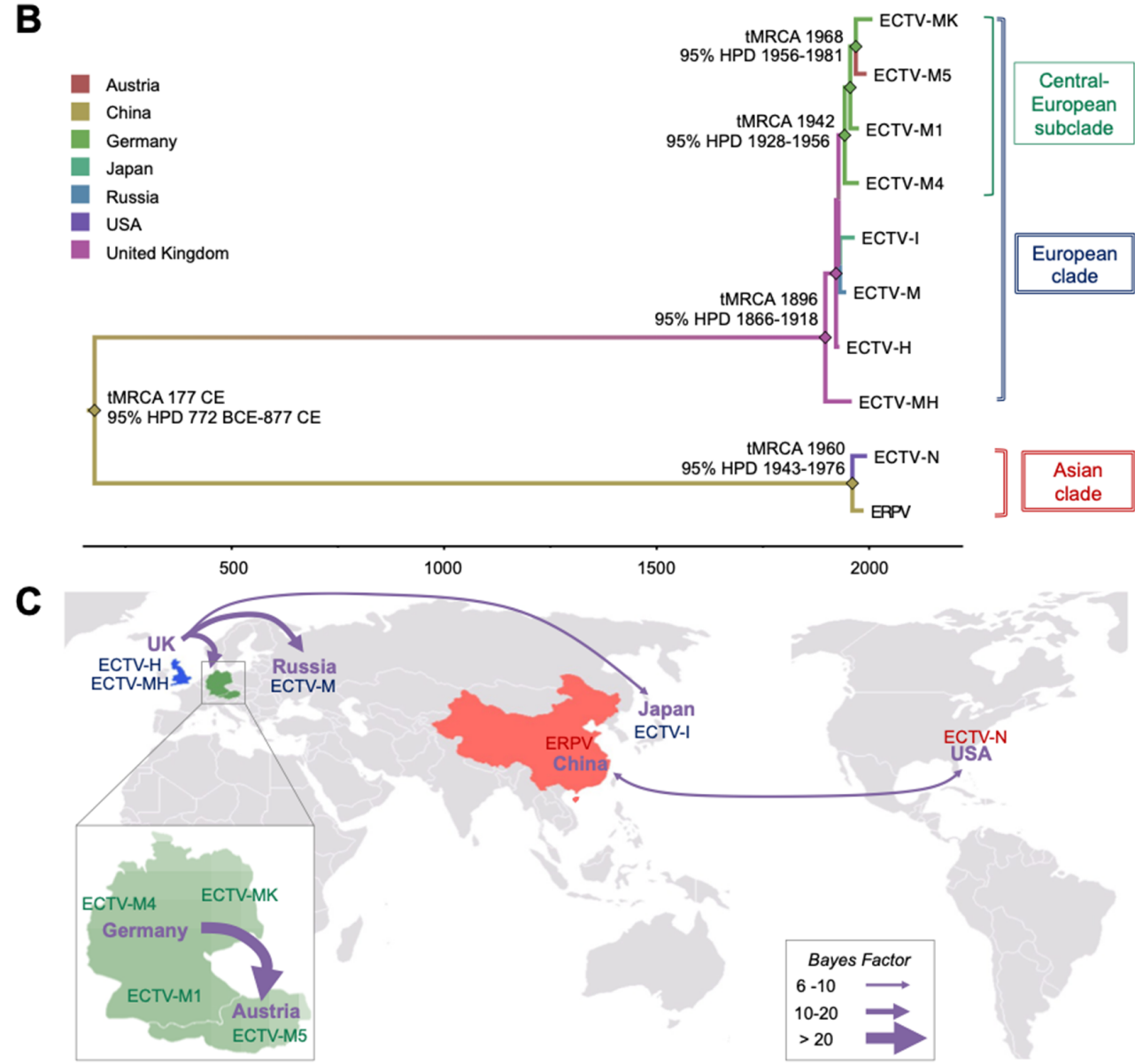

Figure 3. Genomic comparison and phylogenetic analysis of ECTV isolates and strains. (A) Genome alignment of ECTVs to the reference genome of ECTV-M, showing $100 \mathrm{bp}$ windows with identities below $99 \%$. Vertical lines indicate single nt changes as compared to ECTV-M. The white box in ECTV-HE indicates the absence of that particular genomic region as compared to the other strains. In this analysis, regions containing direct sets of repeated sequences, as for the DRI and DRII regions (1-1548; 208,224-209,771 in ECTV-M genome) and the DRIII (reduced to an arbitrary number of 15 repeats for all strains), were not used for the comparison. The low genomic similarity between the ECTV-M and CPXV-Brighton Red (CPXV-BR) is shown to emphasize the high genome similarity among the ECTV isolates and strains. (B) Maximum clade credibility (MCC) tree of $64 \mathrm{kbp}$ of the central region of the genome of all ECTVs whose genome is shown. Branches are colored based on country of origin, diamonds indicate PP $>0.9$ and their color indicates the country of origin for the time most common ancestor (tMRCA). (C) The map shows the origin and the spread of ECTV causing outbreaks in laboratory mouse colonies worldwide based on Bayesian phylogeographic analysis. Arrows represent the spread of ECTV among countries and the color is based on BSSVS values for the movement. Enlarged parts of the map show the main ECTV reservoirs in the European continent where ECTV-M1-M4-M5 and MK strains have been circulating. 
Table 4. Bayesian phylogeographic analysis.

\begin{tabular}{ccc}
\hline Transition & Bayes Factor & Evidence against $\boldsymbol{H}_{\mathbf{0}}$ \\
\hline Germany to Austria & 460.2 & very strong evidence \\
\hline United Kingdom to Russia & 17.1 & strong evidence \\
\hline United Kingdom to Germany & 14.5 & strong evidence \\
\hline China to USA & 9.9 & evidence \\
\hline United Kingdom to Japan & 7.5 & evidence \\
\hline USA to China & 7.2 & evidence \\
\hline Russia to Japan & 4.1 & weak evidence \\
\hline USA to United Kingdom & 3.2 & weak evidence \\
\hline
\end{tabular}

The strength of evidence against the null hypothesis $\left(H_{0}\right)$ was evaluated via MLE comparison with the more complex model $\left(H_{A}\right)$, referred to as the Bayes Factor $(\mathrm{BF})$, wherein $\ln \mathrm{BF}<2$ indicates no evidence against $H_{0} ; 2-6$ - weak evidence; 6-10-evidence; $10-20$ — strong evidence, and $>20$ indicates very strong evidence [57].

\subsection{ECTV-HE Evolved from ECTV-H through a Genomic Re-Organization}

Comparison by dot plot analysis of ECTV-H and ECTV-HE, a strain derived from ECTV-H after serial passages in CAMs, revealed an intra-genomic recombination between the left and right terminal regions (Figure $4 \mathrm{~A}$ ). As a result, a fragment of $10 \mathrm{kbp}$ from the left end of the genome, containing eight genes, had been replaced by a region from the other end of the genome that encompasses three genes that appear now duplicated in ECTV-HE (Figures $3 \mathrm{~A}$ and $4 \mathrm{~B}$ ). This genomic reorganization likely occurred during the multiple passages of ECTV-H in CAMs and is supported by the presence of several reads in ECTV-HE which contain the repeated terminal region fused to unique sequences from the central region (Figure 4C).

\subsection{Identification of Putative Virulence and Anti-Inflammatory Proteins}

The analysis of truncated genes (including pseudogenes that might not translate into active proteins) among strains that have shown different virulence or pathogenesis in vivo may allow the identification of genes that contribute to the high virulence of some ECTV isolates. That is the case of the highly attenuated ECTV-I that harbored three pseudogenes as compared to the full-length versions present in ECTV-M. We hypothesized that any of these genes might be responsible for its attenuated phenotype in BALB/cJ mice (Figure 5A, Table S3). In particular, one of these genes, EVI003P, has a frame-shift that leads to the loss of 90 amino acid (aa) from the C-terminus of an ankyrin-like protein. The full-length version of the orthologue in ECTV-M (EVM002) inhibits NF- $k B$ activation and plays an important role in the pathogenesis of this virus [43]. The ECTV-HE genome, due to the intra-genomic reorganization, lost eight genes that encode for known immunomodulatory proteins such as the viral CD30, viral growth factor, a smallpox virus-encoded chemokine receptor (SECRET) domain-containing protein, a kelch-like protein and two ankyrin like proteins with unknown function (Figure 5A) [41,42,63-66]. Finally, ECTV-MH genome also contains multiple truncated genes that could account of its attenuation in BALB/cJ mice. Among them, there is an orthologue of EVM001, which encodes for the viral chemokine binding protein $35 \mathrm{kDa}$, a well-known immunomodulatory protein in VACV $[67,68]$. The absence of one or several of these genes could account for the highly attenuated phenotype of these three viruses. 


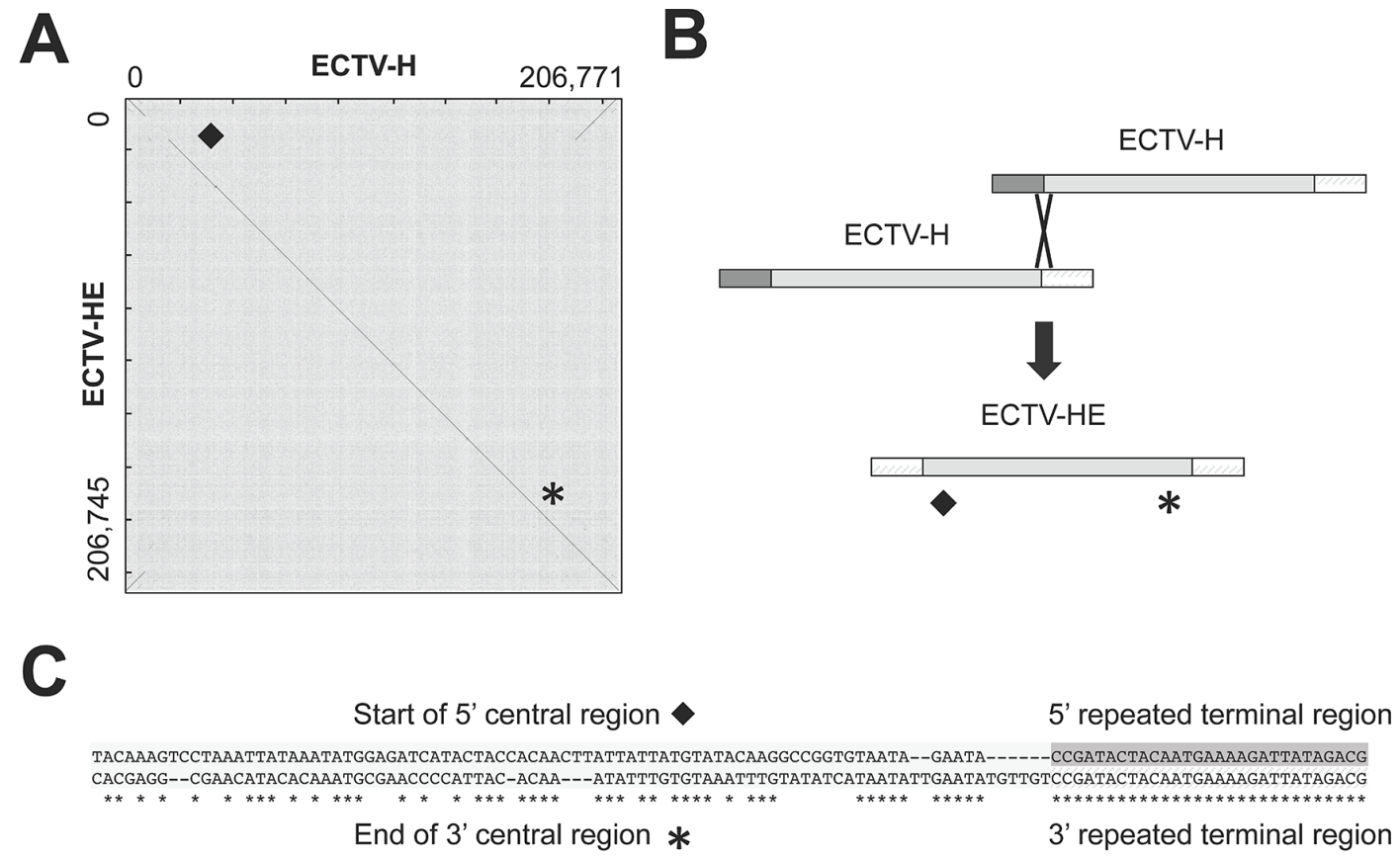

Figure 4. Genomic comparison of ECTV-H and ECTV-HE. (A) Dot plot of ECTV-H vs. ECTV-HE. The dot plot compares two sequences by organizing one sequence on the $\mathrm{x}$-axis, and another on the $\mathrm{y}$-axis, of a plot. When the nt of both sequences match at the same location on the plot, a dot is drawn at the corresponding position. (B) Schematic representation of the proposed genomic recombination between two ECTV-H genomes to generate ECTV-HE. (C) Alignment of two representative reads that share the end of the repeated terminal region of ECTV-HE and differ in the beginning of the central region of the genome. An asterisk and a diamond indicate the approximated region where the aligned reads derived.
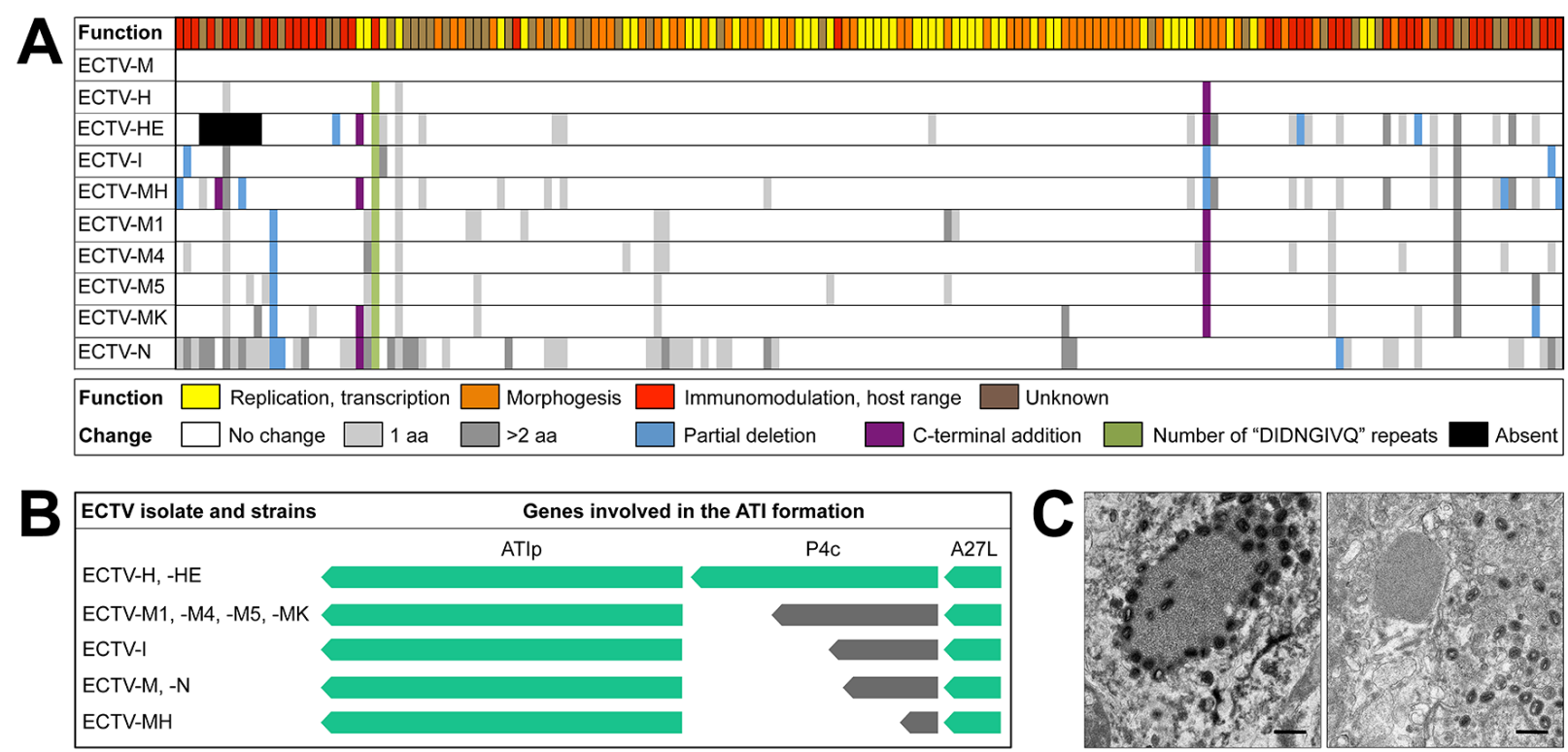

Figure 5. Variability among the proteins encoded by the genomes of the ECTV isolates and strains. (A) Comparison of the protein content: each rectangle represents a protein with aa changes (due to non-synonymous nt mutations) when compared to that of the reference ECTV-M. The color of the upper row rectangles indicates the function of each protein (Function) and the lower row indicates the type of modification (Change). Non-synonymous nt mutations that cause termination of the reading frame are indicated by the light blue color (partial deletion). (B) ECTV genes involved in ATI bodies morphogenesis and virion inclusion process: genes are shown in green and pseudogenes in grey. (C) Electronic micrographs of spleens of mice infected with $10^{3}$ pfu per mice of ECTV-H, (left), and ECTV-M, (right), at 4 dpi. 
The Central-European ECTV-M1, ECTV-M4, ECTV-M5 and ECTV-MK isolates share a common phylogenetic origin. However, ECTV-MK is the only one that does not cause foot swelling. Compared to the gene content of ECTV-M1, ECTV-M4 and ECTVM5, only four mutated genes of ECTV-MK encode for proteins with aa changes. The orthologue of a kelch-like protein described as a virulence factor for ECTV (EVM018) [69], and the Ank/F-box protein involved in inhibition of NFKB (EVM154) [70] showed only single aa changes. Most importantly, two genes with unknown function (EVM169 and EVM11) encode for proteins with a deletion of 40 residues or five consecutive aa changes, respectively (Figure 5A, Table S3). Some of these genes might be responsible for the early control of the inflammatory process during ECTV-MK infections.

\subsection{The Genome of ECTV-H Strain Encodes a Full-Length P4c Protein Required for Viral Inclusion into the ATIS}

Re-sequencing of the ECTV-M genome with the Illumina technology showed that nt at positions 39,775 and 102,467 are erroneous in the previous sequence published by Chen et al. [41] and therefore no difference was considered to be existing at those positions between the genomes of ECTV-M and ECTV-H (Table 5). However, we have found that ECTV-H differs from ECTV-M in $30 \mathrm{nt}$, which are distributed in nine positions along the genome (Tables 3 and 5), affecting the coding region of only four genes: (i) the EVH041 gene, orthologue of EVM025, differs in the number of DIDNGIVQ repeats within the highly variable DRIII region, as previously described for all ECTV isolates (Figure 5A) [34]; (ii) the EVH012 orthologue of EVM008; (iii) the EVH44 orthologue of EVM028, shows a single nt change that translates into a conservative aa change (Table 5); and (iv) the EVH148 gene has a single nt change that eliminates a stop codon present in the pseudogene Region $\mathrm{Q}$ from the ECTV-M genome, coding for a truncated protein of 183 aa, and extends the protein encoded by EVH148 to 503 aa (Table 4). This protein corresponds to the ECTV orthologue of the VACV P4c protein (VACWR149) involved in the inclusion of viral particles into ATI bodies [71] (Figure 5A,B). A full-length p4c protein would be expressed by ECTV-H and ECTV-HE, whereas the other ECTV isolates and strains encode truncated versions of the P4c protein that lack the domain needed to direct the virions towards ATI bodies (Figure 5B). This result provides the genetic basis for the different $\mathrm{V}^{-}$and $\mathrm{V}^{+}$phenotypes previously observed in vitro among ECTV isolates and strains, since only those viruses encoding full-length versions of the P4c protein include their virions into ATIs. Consistently with the $\mathrm{V}^{-}$and $\mathrm{V}^{+}$phenotypes observed in vitro spleen cells from ECTV-H-infected mice showed intracellular mature virions occluded inside or in the periphery of ATI bodies $\left(\mathrm{V}^{+}\right.$phenotype) and ATI bodies from spleen cells of mice infected with ECTV-M showed a $\mathrm{V}^{-}$phenotype (Figure $5 \mathrm{C}$ ). 
Table 5. Differences at the nt and aa level between the ECTV-M and ECTV-H genomes.

\begin{tabular}{|c|c|c|c|c|c|c|}
\hline \multicolumn{4}{|c|}{ ECTV-M } & \multicolumn{2}{|c|}{ ECTV-H } & \multirow[t]{2}{*}{ aa Change } \\
\hline nt & ORF & Published ${ }^{a}$ & Re-Sequenced $^{b}$ & ORF & Sequenced & \\
\hline 13,526 & EVM008 & $\mathrm{A}$ & $\mathrm{A}$ & EVH012 & G & V164A \\
\hline 39,775 & EVM025 & $\mathrm{A}$ & C & EVH041 & $\mathrm{C}$ & \\
\hline 41,907 & EVM028 & $\mathrm{T}$ & $\mathrm{T}$ & EVH044 & $\mathrm{C}$ & $\mathrm{I} 258 \mathrm{~V}$ \\
\hline 59,134 & Intergenic & ATAAGATAAG & - & Intergenic & - & \\
\hline 102,467 & EVM089 & $\mathrm{T}$ & A & EVH107 & A & \\
\hline 147,842 & Region Q & $\mathrm{T}$ & - & EVH148 & G & Stop183G \\
\hline 157,777 & Region S & $21 \times C$ & - & EVH167P & $10 \times C$ & \\
\hline 189,000 & Region Y & $\mathrm{T}$ & - & EVH195P & TAT & \\
\hline 191,424 & Region Y & $\mathrm{A}$ & - & EVH195P & $\mathrm{AT}$ & \\
\hline 195,294 & Region Z & G & - & EVH198P & $\mathrm{T}$ & \\
\hline
\end{tabular}

${ }^{\mathrm{a}}$ Chen et al. [42] ${ }^{\mathrm{b}}$ Sequenced in this study with Illumina technology.

\subsection{In Vivo Dissemination and Transmission of ECTV-M Is More Efficient Than ECTV-H}

The role that ATI bodies play in the life cycle of many poxviruses is unclear [28,72,73], but it has been suggested that they might be involved in viral transmission or dissemination processes [74-79]. The predicted functional differences in ECTV-H as compared to ECTV-M are restricted to two conservative amino acid changes, an insertion of a repeated amino acid motif in EVM025 and the expression of a full-length p4b protein (Table 5, Table S3). We took advantage of the fact that a full-length $4 \mathrm{~b}$ protein was the main difference between ECTV-H and ECTV-M to investigate the hypothesis that ATI bodies may play a role in viral dissemination within the infected host. We analyzed the viral load in popliteal lymph nodes, spleen and liver from mice infected s. c. in the footpad with 10 pfu of ECTV-H or ECTV-M (Figure 6A). At $3 \mathrm{dpi}$, both ECTV-H and ECTV-M replicated to high viral titer in popliteal lymph nodes, $5 \times 10^{5} \mathrm{pfu} / \mathrm{g}$ and $6 \times 10^{6} \mathrm{pfu} / \mathrm{g}$, respectively. At $5 \mathrm{dpi}$, ECTV-M replication in the spleen and liver was significantly higher than the level of replication of ECTV-H, suggesting more-efficient intra-host dissemination when virions are not embedded in the ATIs. At $7 \mathrm{dpi}$, both viruses replicated to similar levels in spleen and liver.

We also explored the role of ATI bodies in viral inter-host transmission by studying the ability of ECTV-M and ECTV-H to be transmitted from infected mice to naïve mice housed in the same cage (Figure 6B). Transmission was not detected from infected mice in the early days of infection (2 to $5 \mathrm{dpi}$, group 1) (Figure 6C). Interestingly, ECTV-M transmission from infected mice was significantly more efficient than transmission of ECTV-H during the period of 4-7 dpi (group 2) (Figure 6C). Five out of seven naïve mice exposed to ECTV-M-infected mice showed high titers in the spleen and the infection was lethal in $75 \%$ of the animals by 22 days post-exposure. By contrast, only one mouse exposed to ECTV-H-infected mice developed a detectable infection and no mortality was observed. Both viruses were efficiently transmitted to naïve mice between 6 and 9 dpi (group 3) (Figure 6C). 
A
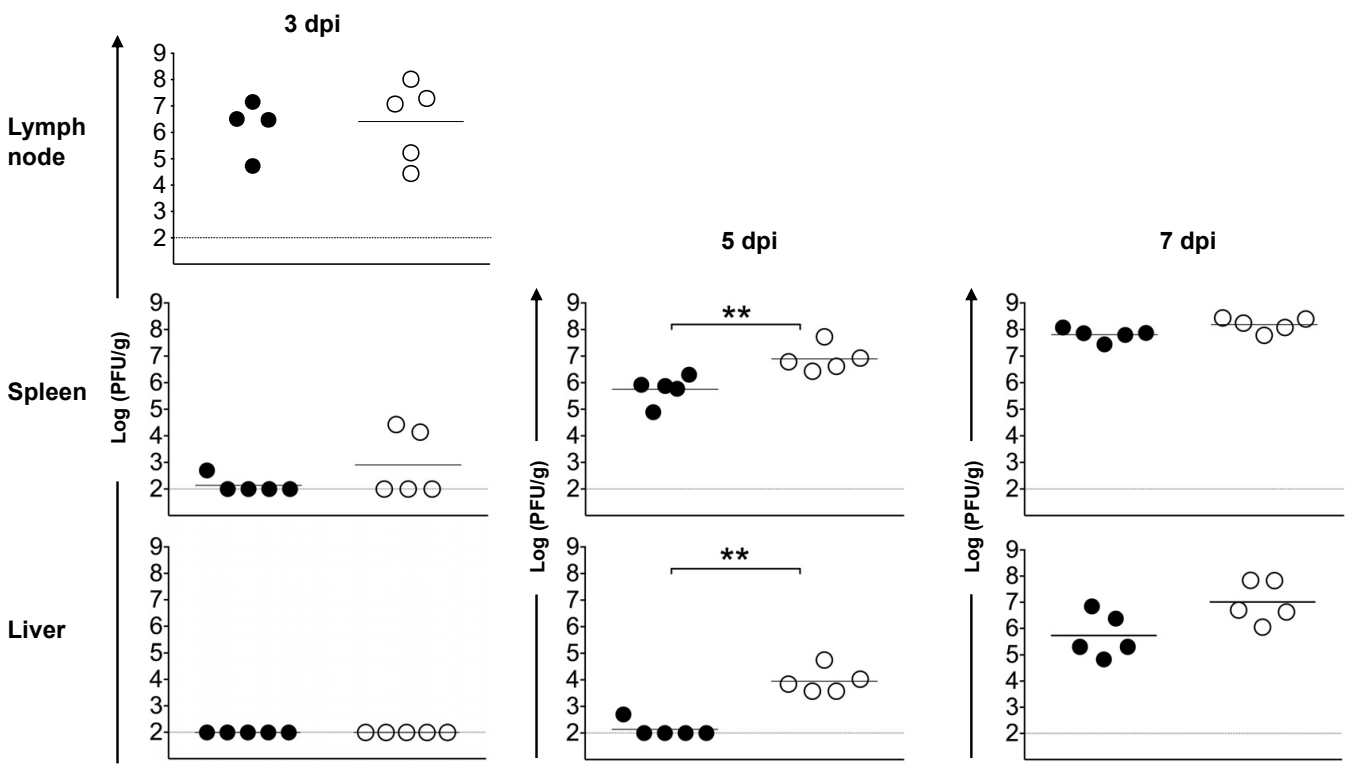

B

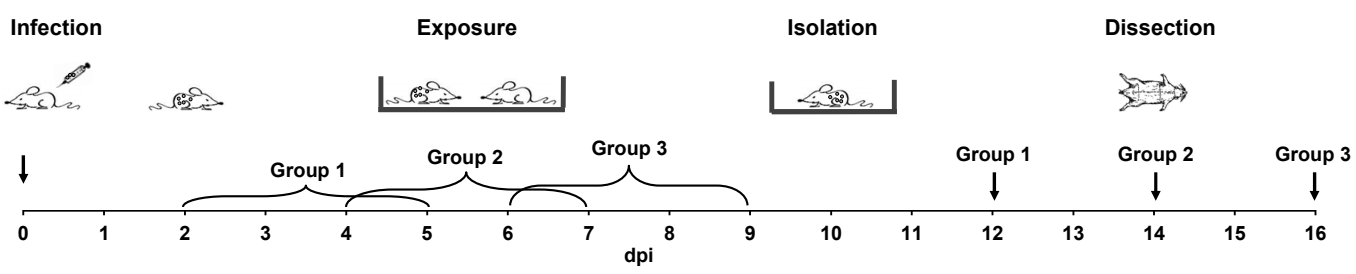

C
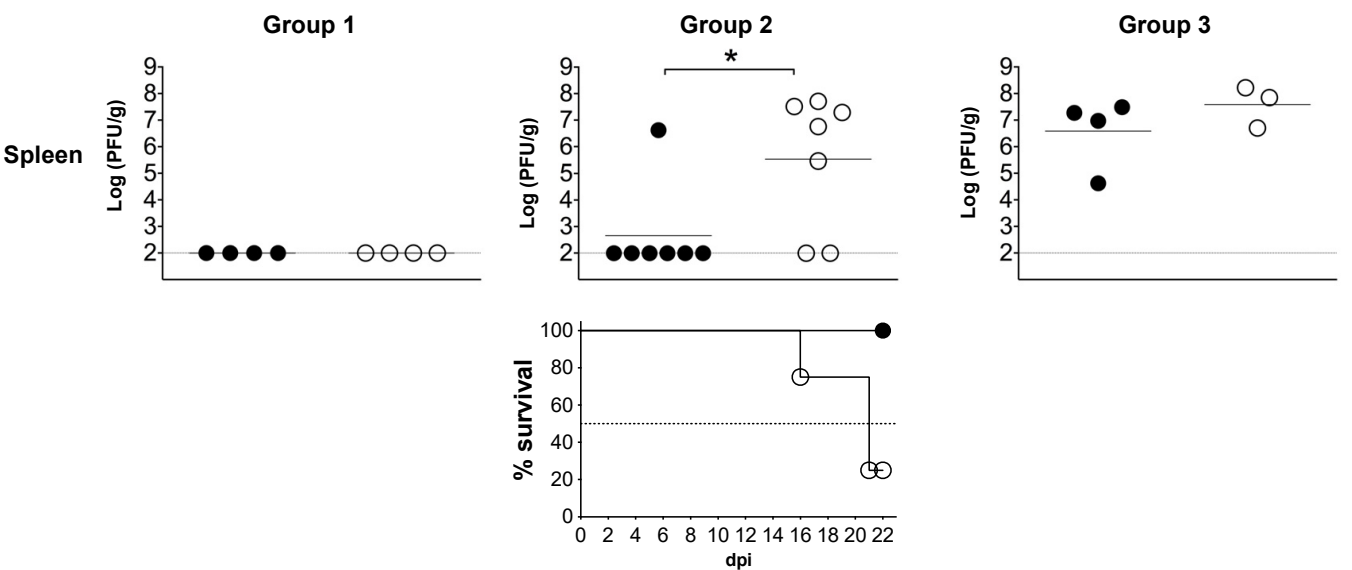

Figure 6. ECTV inclusion into ATI bodies affects its dissemination and transmission. (A) Viral dissemination of ECTV-H (•) and ECTV-M (O) from female BALB/cJ mice s. c. infected in the footpad with 10 pfu. Groups of five ECTV-infected mice were euthanized and virus titer in spleen and liver samples collected at 3,5 and $7 \mathrm{dpi}$, and virus in popliteal lymph nodes at $3 \mathrm{dpi}$, are shown. (B) Schematic representation of the in vivo viral transmission experiment: two infected mice at 2, 4 and 6 dpi were housed with four naïve mice during 3 days. Animals were subsequently separated and 7 days post-exposure (dpe) euthanized to collect spleen samples. Infected and recipient naïve mice shared the same cage during "Exposure", then naïve mice were separated from infected animals ("Isolation") and the viral load was analyzed in the spleen of the naïve mice 7 dpe. Three different protocols of transmission were carried out as schematically shown in the diagrams below the graphs: group 1 of naïve mice was housed with 2-5 dpi infected mice, group 2 with $4-7$ dpi infected mice and group 3 with 6-9 dpi infected mice. (C) Viral transmission from ECTV-M and ECTV-H s. c. infected (10 3 pfu) BALB/cJ mice to naïve mice after 3 days of exposure in the same cage. Spleen viral titers are shown at 7 dpe. Viral titers and mortality of group 2 are the result of two independent experiments with 4 and 3 naïve mice, respectively. Statistical significance is shown with ${ }^{*}(p<0.05),{ }^{* *}(p<0.01)$. Black horizontal lines show geometric means. Gray horizontal line indicates the limit of detection. 


\section{Discussion}

Our study reports the genomic and phylogeographic analysis of a collection of ECTV isolates and attenuated variants. Our data is in agreement with the hypothesis that the constant exchange of biologic material, such as cells, tissues and serum, from laboratories in UK and laboratories in Europe, Japan and USA caused the first wave of ECTV outbreaks between the 1930s and the 1980s, whereas the most recent outbreaks in USA were caused by an independent introduction of mouse serum from China [34]. The $\mathrm{V}^{+}$phenotype of ECTV-NIH79, a strain responsible for an outbreak in USA in the 1980s, is in line with the hypothesis that the early USA outbreaks were caused by material contaminated with ECTV$\mathrm{H}$, the only isolate with this $\mathrm{V}^{+}$phenotype [4]. Similarly, our Bayesian phylogeographic analysis suggests that the introduction of ECTV in Russia might have been caused by material contaminated with ECTV-H. ECTV-M and ECTV-H differ only in $30 \mathrm{nt}$ mutations presumably introduced in ECTV-M and not found in other ECTV isolates from the European clade. Hence, we propose that these mutations might have been acquired by ECTV-M during subsequent cell culture amplification of the original ECTV-H isolate. The origin of ECTV-MH is uncertain. Unlike all other ECTVs, ECTV-MH presents a full-length EVMH010 gene that encodes a C-type lectin suggesting an ancient origin of this virus within the species. However, we cannot rule out the possibility that ECTV-MH, like ECTV-HE, was originated after extensive passage of ECTV-H, or a closely related virus, in CAMs. Moreover, ECTV-MH may be related to ECTV-HE since these viruses share the same mutations introduced in many genes as compared with ECTV-H, including the restoration of the ECTV-M pseudogene Region N (full-length gene EVN038 in ECTV-N). Similarly, the genomic sequence of ECTV-I is consistent with this strain being derived from ECTV-H after serial tissue culture passages and the introduction of mutations. This strain is the most closely related to ECTV-H among the attenuated strains, differing only in $138 \mathrm{nt}$. Our Bayesian phylogeographic analysis evidenced that the importation of ECTV in Japan likely occurred from the UK.

The genomic sequence and virulence of ECTV-MK in a susceptible mouse model provides unprecedented information on ECTV natural infections. The finding of ECTV-MK infecting a wild mouse in the same European region where ECTV-M1, ECTV-M4 and ECTV-M5 were isolated, suggests that direct contact of laboratory and wild mice infected with ECTV-M1/-M4/-M5/MK-like viruses might have caused these outbreaks [24,25]. These isolates have not been passed extensively in cell culture, and therefore their genomes should be very close to the natural circulating viruses. In 1962, a mousepox record in wild mice in Germany was reported [4,39]. However, the presence of ECTV was not confirmed by genomic sequencing and therefore there is no definitive demonstration that ECTV caused that infection in wild mice $[4,39]$. The existence of a recombinant virus of ECTV and CPXV, CPXV-No-H2, isolated from a human patient in Norway, was reported to have ECTV sequences as a result of recombination events between CPXV and ECTV. This raised the possibility of a reservoir for ECTV in that country, although no evidence of infections in wild mice were reported [80]. We therefore report the first demonstration of ECTV isolation from wild mice, in the region of Krefeld in Germany in 2008. As it is known, ECTV infects susceptible and resistant laboratory mouse strains (M. musculus) and these strains result from the genetic interchange of wild mice strains from Europe and Asia [13,81]. The wild mouse species infected with ECTV-MK is unknown, and the most probable candidates are M. musculus domesticus or M. musculus musculus, which are common in central Europe and showed moderate resistance to ECTV-NIH79 [82]. The existence of mice infected with ECTV in China has been reported since the 1960s, although the natural source remains unknown $[34,37,83]$. The split between ECTVs from the European and Asiatic clades dates back to $177 \mathrm{CE}$ and reflects the large genetic distance between the two clades, possibly a consequence of the long adaptation process to geographically and genetically different mouse strains [84].

Our study constitutes the first comprehensive evaluation of the in vivo phenotype of a collection of ECTV isolates and strains in the same mouse model. The potential 
influence of mouse sex in the susceptibility to ECTV infection should be addressed in the future, although to our knowledge there is no evidence for a major effect of sex on ECTV susceptibility in this mousepox model. The integration of the full genome sequence information of the ECTVs with their pathogenesis in the classical mousepox model of susceptible BALB/CJ mice and replicative properties in tissue culture led us to identify a set of putative host-interaction genes including molecular determinants of virulence. A candidate gene for inducing fusion of BS-C-1 infected cells leading to a faster in vitro replication of ECTV-M5 and ECTV-M1 is EVM5-115/EVM1-115. These genes share sequence differences with the corresponding genes of the related ECTV-M4 or ECTVMK that exhibit a slower replication cycle and encode for an orthologue of the VACV Copenhagen strain D8 gene [85]. The D8 protein shows sequence similarity to a cellular carbonic anhydrase (EC 4.2.1.1), and the mutations $\mathrm{Y} 69 \mathrm{H}$ and $\mathrm{Y} 92 \mathrm{H}$ increase the activity of the protein and viral replication in vitro [86,87]. The proteins encoded by EVM1-115 and EVM5-115 show mutations (H67R and S206- in EVM1-115; N175K in EVM5-115) that could account for enhancement of its carbonic anhydrase and the subsequent decrease of the $\mathrm{pH}$ of the cell facilitating cell fusion mediated by A17 and A27, and ultimately boosting of viral replication.

Similarly to other CAM-adapted strains such as Chorioallantois VACV Ankara and modified VACV Ankara, we reported the loss of several genes encoding for ankyrin-like or kelch proteins as responsible for the attenuation of ECTV-MH and ECTV-HE [69,88-94]. The former encodes also for a truncated version of the viral chemokine binding protein 35K [16], whose ortholog in VACV reduces host inflammation in the lung of infected mice [68]. A candidate gene responsible for the ECTV-I attenuation and strong inflammatory response at the site of infection is EVM002, since this is the only gene of ECTV-I truncated in comparison with other virulent ECTVs and it has been involved in the blockade of NF- $k \mathrm{~B}$ [43]. However, the milder inflammation observed in mice infected with ECTV-MH as compared to ECTV-I suggested that EVM002 is a stronger anti-inflammatory mediator than EVM001 and other genes truncated of ECTV-MH. The absence of a functional protein encoded by EVM002 is likely involved in the characteristic amputation that named the virus "ectromelia" in ECTV-I. This amputation had been previously described in three-week old mice infected with ECTV-H [39]. The older age of the mice used in our experiments might explain the absence of amputation observed in ECTV-H. It would be of interest to further investigate whether the attenuated phenotype is due to loss of function of one or more than one of these candidate genes.

ECTV virulent strains encode several anti-inflammatory proteins that prevent local swelling a few days after infection such as $\mathrm{CrmD}$ or the type I interferon binding protein $[43,45,46,64,95,96]$. ECTV isolates from the Central European subclade (ECTV-M1, ECTV-M4 and ECTV-M5) infections elicited an early footpad swelling even in animals infected with lethal doses. Interestingly, the genetically and geographically related ECTV-MK, isolated from a wild mouse, exhibited a complete blockade of footpad swelling. By comparing their gene content, we identified two genes with novel putative anti-inflammatory properties: EVMK017 (EVM011) and EVMK199 (EVM169). EVMK017 encodes an orthologue of VACV Copenhagen strain C10, a protein that has a region between aa 316 and 327 with sequence similarity to the IL-1 receptor antagonist, and it has been suggested, although not experimentally demonstrated, that this region of C10 may interact with the IL-1 receptor and block its function [97]. The EVMK017 protein presents a cluster of five aa changes in positions that correspond to this $\mathrm{C} 10$ region, suggesting that this protein, if demonstrated that it interacts with the IL-1 receptor, could be involved in the inhibition of the IL-1 signaling pathway [97]. The second gene, EVMK199, encodes the largest orthopoxvirus protein [98], a protein shown to block T cell activation and to contribute to virulence $[99,100]$. EVMK199 shows a 40 aa deletion in the same region where its homologue in ECTV-M5 has seven nearly consecutive aa changes. This might explain why ECTV-M5 also prevented inflammation at low dosages. The implication of these genes in 
poxvirus pathology is evidenced by the attenuated phenotype observed in fowlpox strains with truncated versions of the orthologous genes of EVMK017 and EVMK199 [88].

We also addressed the virulence exhibited by ECTV-H and ECTV-M during infection of BALB/cJ mice and a dose-independence lethality of the former despite sharing almost identical genomes. Based on their genome sequences and on in vitro and in vivo phenotypes, we hypothesize that the inclusion of ECTV-H virions into the ATIs, mediated by the full-length version of the P4c protein encoded by the EVH148 gene, may be responsible for the unpredictable virulence phenotype displayed by ECTV-H. The P4c protein plays a major role in the process of occlusion of the virions into the ATI bodies [75]. ECTV-H and ECTV-M replicate in mice to similar levels early after infection in lymph nodes. The truncation of the gene encoding P4c in ECTV-M, and in all the other ECTV isolates and strains, may accelerate the viral intra-host dissemination and enhance viral transmission among hosts, whereas the presence of a P4c full-length protein in ECTV-H directs virions to ATI bodies and may reduce their ability to disseminate within the mouse and transmit to other mice.

In contrast to the ECTV isolated after the ECTV-H outbreak of 1930 in London, which has a $\mathrm{V}^{+}$phenotype, the ECTVs that were transferred from this initial source to other laboratories, such as ECTV-M or ECTV-I, have a $\mathrm{V}^{-}$phenotype. The selection of a $\mathrm{V}^{-}$ phenotype may be the consequence of a more rapid replication and dissemination in cell culture and mice of the $\mathrm{V}^{-}$variants $[75,79]$. Consistent with this, the three isolates from the Central European subclade (ECTV-M1, ECTV-M4 and ECTV-M5) all have a $\mathrm{V}^{-}$phenotype that may have facilitated transmission to mouse colonies in animal house facilities. The possibility that poxviruses occluded in ATI bodies and incorporated by phagocytic cells may escape the lysosome degradation pathway exploiting the A17-A27 fusion activity at low $\mathrm{pH}$ suggests that embedding of virus particles into ATI bodies may facilitate a non-specific mechanism of viral entry $[76,85]$. Accordingly, CPXV shows broad host range and presents a $\mathrm{V}^{+}$phenotype, while VARV and ECTV are host-specialized viruses and exhibit $\mathrm{V}^{-}$phenotype, except for ECTV-H [101]. As classical host-range studies have not been performed for ECTV, we do not know whether ATI bodies may actually represent a non-specific mechanism of viral entry and broaden ECTV-H's host range. It remains to be explored whether the frequently reported hypothesis that occlusion of virions into ATI bodies provide some other advantage related to the physical resistance of virions out of the animals and a long-term transmission of the virus. Consistently with the virulence phenotype of ECTV-M and ECTV-H, CPXV lacking the ability to occlude into ATI bodies is more virulent than the variant that does occlude into ATI bodies [79]. Therefore, ATI bodies might be a viral self-contention mechanism that ensures host survival and persistence in natural reservoirs.

In summary, this is the first comprehensive report that sheds light into the phylogenetic relationship of the worldwide outbreaks caused by ECTV, and we show that the first ECTV isolated from a wild mouse, ECTV-MK, is related to a Central European subclade. Genome sequencing and pathogenesis studies have identified ECTV genes that may contribute to virulence or control the host inflammatory response. We show that most of the ECTV isolates and strains cannot recruit virions to ATIs, and this may enhance their transmission efficiency.

Supplementary Materials: The following are available online at https://www.mdpi.com/article/ 10.3390/v13061146/s1, Figure S1: Regression analysis of temporal resolution of ECTV sequence dataset., Table S1: Survival for figure 1., Table S2: DBA/2 mice survival, Table S3: Comparative analysis of the proteins encoded by ECTV-Moscow, ECTV-Naval and the ECTVs from this study.

Author Contributions: A.A. conceived the project and collected all ECTV isolates and strains. C.M., A.L.-B. and A.A. designed the experiments. C.M. and A.L.-B. performed the experiments, with participation of A.A. in the infection of mice and R.M. in in vitro experiments. A.N. isolated and sequenced the ECTV-MK strain. C.M. performed Bayesian phylogeography analyses. All authors contributed to the preparation of the manuscript. All authors have read and agreed to the published version of the manuscript. 
Funding: This work was funded by the Spanish Ministry of Economy and Competitiveness (grant SAF2012-38957) and Spanish Ministry of Science and Innovation, and European Union (European Regional Development's Funds, FEDER) (grant RTI2018-097581-B-I00).

Institutional Review Board Statement: All animal experiments were performed with special efforts to minimize animal suffering, in compliance with national and international regulations and were approved by the Ethical Review Board of Consejo Superior de Investigaciones Científicas and Comunidad de Madrid under reference PROEX 025/16 (21 March 2016).

Informed Consent Statement: Not applicable.

Data Availability Statement: The genome of ECTV-H was submitted to GenBank with the accession number KY554976.1, and ECTV-HE, ECTV-MH, ECTV-I, ECTV-M1, ECTV-M4, ECTV-M5 and ECTVMK were deposited to the European Nucleotide Archive (ENA) with accession number PRJEB44436.

Acknowledgments: We thank Juan Alonso Lobo for his help with the animal experiments and the Genomics and NGS Core Facility at Centro de Biología Molecular Severo Ochoa, part of CEI $\mathrm{UAM}+\mathrm{CSIC}$, for their advice and the annotation and data submission of the ECTV sequences reported here.

Conflicts of Interest: The authors declare no conflict of interest.

\section{References}

1. Constantin, C.M.; Martinelli, A.M.; Bonney, E.A.; Strickland, O.L. Smallpox: An update for nurses. Biol. Res. Nurs. 2003, 4, 282-294. [CrossRef] [PubMed]

2. Downie, A.W. Jenner's cowpox inoculation. Br. Med. J. 1951, 2, 251-256. [CrossRef] [PubMed]

3. Paran, N.; Sutter, G. Smallpox vaccines: New formulations and revised strategies for vaccination. Hum. Vaccines 2009 , 5, 824-831. [CrossRef]

4. Fenner, F.; Wittek, R.; Dumbell, K.R. The Orhopoxviruses; Elsevier: Amsterdam, The Netherlands, 1989.

5. Henderson, D.A. Smallpox Virus Destruction and the Implications of a New Vaccine. Biosecur. Bioterror. Biodef. Strat. Pract. Sci. 2011, 9, 163-168. [CrossRef] [PubMed]

6. Beer, E.M.; Rao, V.B. A systematic review of the epidemiology of human monkeypox outbreaks and implications for outbreak strategy. PLoS Negl. Trop. Dis. 2019, 13, e0007791. [CrossRef]

7. Silva, N.I.O.; de Oliveira, J.S.; Kroon, E.G.; Trindade, G.D.S.; Drumond, B.P. Here, There, and Everywhere: The Wide Host Range and Geographic Distribution of Zoonotic Orthopoxviruses. Viruses 2020, 13, 43. [CrossRef]

8. Marchal, J. Infectious ectromelia. A hitherto undescribed virus disease of mice. J. Pathol. Bacteriol. 1930, 33, 713-728. [CrossRef]

9. Buller, R.M. Mousepox: A Small Animal Model for Biodefense Research. Appl. Biosaf. 2004, 9, 10-19. [CrossRef]

10. Sigal, L.J. The Pathogenesis and Immunobiology of Mousepox. Adv. Immunol. 2016, 129, 251-276. [CrossRef]

11. Lipman, N.S.; Nguyen, H.; Perkins, S. Mousepox: A threat to mouse colonies. Lab. Anim. 1999, 33, 304. [CrossRef]

12. Fenner, F. Mousepox (infectious ectromelia): Past, present, and future. Lab. Anim. Sci. 1981, 31, 553-559.

13. Esteban, D.J.; Buller, R.M.L. Ectromelia virus: The causative agent of mousepox. J. Gen. Virol. 2005, 86, 2645-2659. [CrossRef] [PubMed]

14. Wallace, G.D. The threat of mouse pox. J. Immunol. 1981, 126, 1648. [CrossRef]

15. Fenner, F. Studies in mousepox, infectious ectromelia of mice; a comparison of the virulence and infectivity of three strains of ectromelia virus. Aust. J. Exp. Biol. Med. Sci. 1949, 27, 31-43. [CrossRef] [PubMed]

16. Sith, V.P.; Alcami, A. Expression of Secreted Cytokine and Chemokine Inhibitors by Ectromelia Virus. J. Virol. 2000, 74, 8460-8471. [CrossRef]

17. Andrewes, C.H.; Elford, W.J. Infections ectromelia; experiments on interference and immunization. Br. J. Exp. Pathol. 1947, 28, 278-285. [PubMed]

18. Fenner, F. Studies in mousepox, infectious ectromelia of mice; quantitative investigations on the spread of virus through the host in actively and passively immunized animals. Aust. J. Exp. Biol. Med. Sci. 1949, 27, 1-18. [CrossRef] [PubMed]

19. Fenner, F. The Pathogenesis of the Acute Exanthems an Interpretation Based on Experimental Investigations with Mousepox (Infectious Ectromelia of Mice). Lancet 1948, 252, 915-920. [CrossRef]

20. Fenner, F. Studies in infectious ectromelia in mice; natural transmission; the portal of entry of the virus. Aust. J. Exp. Biol. Med. Sci. 1947, 25, 275-282. [CrossRef] [PubMed]

21. Fenner, F. Studies in infectious ectromelia in mice (mouse pox) natural transmission; elimination of the virus. Aust. J. Exp. Biol. Med. Sci. 1947, 25, 327-335. [CrossRef]

22. Fenner, F.; Fenner, E.M. Studies in mousepox, infectious ectromelia of mice; closed epidemics in herds of normal and vaccinated mice. Aust. J. Exp. Biol. Med. Sci. 1949, 27, 19-30. [CrossRef]

23. Fenner, F. Studies in mousepox (Infectious ectromelia of mice). J. Immunol. 1949, 63, 341-373.

24. Mahnel, H. Disinfection for viruses. Zent. Veterinärmedizin Reihe B J. Vet. Med. Ser. B 1983, 30, 81-96. [CrossRef] 
25. Osterrieder, N.; Meyer, H.; Pfeffer, M. Characterization of the gene encoding the A-type inclusion body protein of mousepox virus. Virus Genes 1994, 8, 125-135. [CrossRef] [PubMed]

26. de Faundez, I.S.; Niemialtowski, M. Electron microscopy, plaque assay and preliminary serological characterization of three ectromelia virus strains isolated in Poland in the period 1986-1988. Arch. Virol. 1990, 114, 285-291. [CrossRef] [PubMed]

27. Mavian, C.; López-Bueno, A.; Alcamí, A. Genome Sequence of WAU86/88-1, a New Variant of Vaccinia Virus Lister Strain from Poland. Genome Announc. 2014, 2. [CrossRef] [PubMed]

28. Ichihashi, Y.; Matsumoto, S. Studies on the nature of marchal bodies (A-type inclusion) during ectromelia virus infection. Virology 1966, 29, 264-275. [CrossRef]

29. Fenner, F. Mouse-pox; infectious ectromelia of mice; a review. J. Immunol. 1949, 63, 341-373.

30. Trentin, J.J.; Briody, B.A. An outbreak of mouse-pox (infectious estromelia) in the United States. II. Definitive diagnosis. Science 1953, 117, 227-228. [CrossRef]

31. Allen, A.M.; Clarke, G.L.; Ganaway, J.R.; Lock, A.; Werner, R.M. Pathology and diagnosis of mousepox. Lab. Anim. Sci. 1981, 31, 599-608.

32. Small, J.D.; New, A.E. Prevention and control of mousepox. Lab. Anim. Sci. 1981, 31, 616-629. [PubMed]

33. Labelle, P.; Hahn, N.E.; Fraser, J.K.; Kendall, L.V.; Ziman, M.; James, E.; Shastri, N.; Griffey, S.M. Mousepox Detected in a Research Facility: Case Report and Failure of Mouse Antibody Production Testing to Identify Ectromelia Virus in Contaminated Mouse Serum. Comp. Med. 2009, 59, 180-186. [PubMed]

34. Mavian, C.; López-Bueno, A.; Bryant, N.A.; Seeger, K.; Quail, M.A.; Harris, D.; Barrell, B.; Alcami, A. The genome sequence of ectromelia virus Naval and Cornell isolates from outbreaks in North America. Virology 2014, 462-463, 218-226. [CrossRef]

35. Dick, E.J.; Kittell, C.L.; Meyer, H.; Farrar, P.L.; Ropp, S.L.; Esposito, J.J.; Buller, R.M.; Neubauer, H.; Kang, Y.H.; McKee, A.E. Mousepox outbreak in a laboratory mouse colony. Lab. Anim. Sci. 1996, 46, 602-611.

36. Lipman, N.S.; Perkins, S.; Nguyen, H.; Pfeffer, M.; Meyer, H. Mousepox resulting from use of ectromelia virus-contaminated, imported mouse serum. Comp. Med. 2000, 50, 426-435. [PubMed]

37. Mendez-Rios, J.D.; Martens, C.A.; Bruno, D.P.; Porcella, S.F.; Zheng, Z.-M.; Moss, B. Genome Sequence of Erythromelalgia-Related Poxvirus Identifies it as an Ectromelia Virus Strain. PLoS ONE 2012, 7, e34604. [CrossRef]

38. Neubauer, H.; Pfeffer, M.; Meyer, H. Specific detection of mousepox virus by polymerase chain reaction. Lab. Anim. 1997, 31, 201-205. [CrossRef]

39. Groppel, K. The occurrence of ectromelia (mousepox) in wild mice. Arch. Exp. Vet. 1962, 16, $243-278$.

40. Carroll, D.S.; Emerson, G.L.; Li, Y.; Sammons, S.; Olson, V.; Frace, M.; Nakazawa, Y.; Czerny, C.P.; Tryland, M.; Kolodziejek, J.; et al. Chasing Jenner's vaccine: Revisiting cowpox virus classification. PLoS ONE 2011, 6, e23086. [CrossRef]

41. Chen, N.; Danila, M.I.; Feng, Z.; Buller, R.L.; Wang, C.; Han, X.; Lefkowitz, E.J.; Upton, C. The genomic sequence of ectromelia virus, the causative agent of mousepox. Virology 2003, 317, 165-186. [CrossRef]

42. Alejo, A.; Saraiva, M.; Ruiz-Argüello, M.B.; Viejo-Borbolla, A.; de Marco, M.F.; Salguero, F.J.; Alcami, A. A Method for the Generation of Ectromelia Virus (ECTV) Recombinants: In Vivo Analysis of ECTV vCD30 Deletion Mutants. PLoS ONE 2009, 4, e5175. [CrossRef] [PubMed]

43. Rubio, D.; Xu, R.-H.; Remakus, S.; Krouse, T.E.; Truckenmiller, M.E.; Thapa, R.J.; Balachandran, S.; Alcamí, A.; Norbury, C.C.; Sigal, L.J. Crosstalk between the Type 1 Interferon and Nuclear Factor Kappa B Pathways Confers Resistance to a Lethal Virus Infection. Cell Host Microbe 2013, 13, 701-710. [CrossRef] [PubMed]

44. van Buuren, N.; Burles, K.; Schriewer, J.; Mehta, N.; Parker, S.; Buller, R.M.; Barry, M. EVM005: An ectromelia-encoded protein with dual roles in NF-kappaB inhibition and virulence. PLoS Pathog. 2014, 10, e1004326. [CrossRef]

45. Xu, R.-H.; Cohen, M.; Tang, Y.; Lazear, E.; Whitbeck, J.C.; Eisenberg, R.J.; Cohen, G.H.; Sigal, L.J. The orthopoxvirus type I IFN binding protein is essential for virulence and an effective target for vaccination. J. Exp. Med. 2008, 205, 981-992. [CrossRef]

46. Alejo, A.; Ruiz-Argüello, M.B.; Pontejo, S.M.; de Marco, M.D.M.; Saraiva, M.; Hernaez, B.; Alcamí, A. Chemokines cooperate with TNF to provide protective anti-viral immunity and to enhance inflammation. Nat. Commun. 2018, 9, 1-16. [CrossRef]

47. Myskiw, C.; Arsenio, J.; Hammett, C.; van Bruggen, R.; Deschambault, Y.; Beausoleil, N.; Babiuk, S.; Cao, J. Comparative Analysis of Poxvirus Orthologues of the Vaccinia Virus E3 Protein: Modulation of Protein Kinase R Activity, Cytokine Responses, and Virus Pathogenicity. J. Virol. 2011, 85, 12280-12291. [CrossRef] [PubMed]

48. Alcamí, A.; Smith, G.L. A soluble receptor for interleukin-1 beta encoded by vaccinia virus: A novel mechanism of virus modulation of the host response to infection. Cell 1992, 71, 153-167. [CrossRef]

49. Symons, J.A.; Alcami, A.; Smith, G.L. Vaccinia virus encodes a soluble type I interferon receptor of novel structure and broad species specificity. Cell 1995, 81, 551-560. [CrossRef]

50. Rutherford, K.; Parkhill, J.; Crook, J.; Horsnell, T.; Rice, P.; Rajandream, M.-A.; Barrell, B. Artemis: Sequence visualization and annotation. Bioinformatics 2000, 16, 944-945. [CrossRef]

51. Rambaut, A.; Lam, T.T.; Carvalho, L.M.; Pybus, O.G. Exploring the temporal structure of heterochronous sequences using TempEst (formerly Path-O-Gen). Virus Evol. 2016, 2, vew007. [CrossRef]

52. Nguyen, L.-T.; Schmidt, H.A.; von Haeseler, A.; Minh, B.Q. IQ-TREE: A Fast and Effective Stochastic Algorithm for Estimating Maximum-Likelihood Phylogenies. Mol. Biol. Evol. 2015, 32, 268-274. [CrossRef] 
53. Esposito, J.J.; Sammons, S.A.; Frace, A.M.; Osborne, J.; Olsen-Rasmussen, M.; Zhang, M.; Govil, D.; Damon, I.K.; Kline, R.; Laker, M.; et al. Genome Sequence Diversity and Clues to the Evolution of Variola (Smallpox) Virus. Science 2006, 313, 807-812. [CrossRef]

54. Tamura, K.; Peterson, D.; Peterson, N.; Stecher, G.; Nei, M.; Kumar, S. MEGA5: Molecular evolutionary genetics analysis using maximum likelihood, evolutionary distance, and maximum parsimony methods. Mol. Biol. Evol. 2011, 28, 2731-2739. [CrossRef]

55. Drummond, A.J.; Rambaut, A. BEAST: Bayesian evolutionary analysis by sampling trees. BMC Evol. Biol. 2007, 7, 214. [CrossRef]

56. Gray, R.R.; Tatem, A.J.; Johnson, J.A.; Alekseyenko, A.; Pybus, O.G.; Suchard, M.A.; Salemi, M. Testing Spatiotemporal Hypothesis of Bacterial Evolution Using Methicillin-Resistant Staphylococcus aureus ST239 Genome-wide Data within a Bayesian Framework. Mol. Biol. Evol. 2010, 28, 1593-1603. [CrossRef]

57. Lemey, P.; Rambaut, A.; Drummond, A.J.; Suchard, M.A. Bayesian phylogeography finds its roots. PLoS Comput. Biol. 2009, 5, e1000520. [CrossRef]

58. Bhatt, P.N.; Jacoby, R.O.; Gras, L. Mousepox in inbred mice innately resistant or susceptible to lethal infection with ectromelia virus. IV. Studies with the Moscow strain. Arch. Virol. 1988, 100, 221-230. [CrossRef] [PubMed]

59. Jacoby, R.; Bhatt, P. Mousepox in inbred mice innately resistant or susceptible to lethal infection with ectromelia virus. II. Pathogenesis. Lab. Anim. Sci. 1987, 37, 16-22. [PubMed]

60. Wallace, G.D.; Buller, R.M. Kinetics of ectromelia virus (mousepox) transmission and clinical response in C57BL/6j, BALB/cByj and AKR/J inbred mice. Lab. Anim. Sci. 1985, 35, 41-46. [PubMed]

61. Parker, S.; Siddiqui, A.M.; Oberle, C.; Hembrador, E.; Lanier, R.; Painter, G.; Robertson, A.; Buller, R.M. Mousepox in the C57BL/6 strain provides an improved model for evaluating anti-poxvirus therapies. Virology 2009, 385, 11-21. [CrossRef] [PubMed]

62. Okeke, M.I.; Adekoya, O.A.; Moens, U.; Tryland, M.; Traavik, T.; Nilssen, Ø. Comparative sequence analysis of A-type inclusion (ATI) and P4c proteins of orthopoxviruses that produce typical and atypical ATI phenotypes. Virus Genes 2009, 39, 200-209. [CrossRef] [PubMed]

63. Saraiva, M.; Smith, P.; Fallon, P.; Alcami, A. Inhibition of Type 1 Cytokine-mediated Inflammation by a Soluble CD30 Homologue Encoded by Ectromelia (Mousepox) Virus. J. Exp. Med. 2002, 196, 829-839. [CrossRef] [PubMed]

64. Alejo, A.; Ruiz-Arguello, M.B.; Ho, Y.; Smith, V.P.; Saraiva, M.; Alcami, A. A chemokine-binding domain in the tumor necrosis factor receptor from variola (smallpox) virus. Proc. Natl. Acad. Sci. USA 2006, 103, 5995-6000. [CrossRef] [PubMed]

65. Buller, R.M.; Chakrabarti, S.; Moss, B.; Fredricksont, T. Cell proliferative response to vaccinia virus is mediated by VGF. Virology 1988, 164, 182-192. [CrossRef]

66. Wilton, B.A.; Campbell, S.; van Buuren, N.; Garneau, R.; Furukawa, M.; Xiong, Y.; Barry, M. Ectromelia virus BTB/kelch proteins, EVM150 and EVM167, interact with cullin-3-based ubiquitin ligases. Virology 2008, 374, 82-99. [CrossRef]

67. Alcamía, A.; Symons, J.A.; Collins, P.D.; Williams, T.J.; Smith, G.L. Blockade of chemokine activity by a soluble chemokine binding protein from vaccinia virus. J. Immunol. 1950, 160, 624-633.

68. Reading, P.; Symons, J.A.; Smith, G.L. A Soluble Chemokine-Binding Protein from Vaccinia Virus Reduces Virus Virulence and the Inflammatory Response to Infection. J. Immunol. 2003, 170, 1435-1442. [CrossRef]

69. Kochneva, G.V.; Kolosova, I.; Lupan, T.A.; Sivolobova, G.F.; Yudin, P.V.; Grazhdantseva, A.A.; Ryabchikova, E.I.; Kandrina, N.Y.; Shchelkunov, S.N. Orthopoxvirus genes for Kelch-like proteins: III. Construction of Mousepox (ectromelia) virus variants with targeted gene deletions. Mol. Biol. 2009, 43, 567-572. [CrossRef]

70. Burles, K.; van Buuren, N.; Barry, M. Ectromelia virus encodes a family of Ankyrin/F-box proteins that regulate NFkappaB. Virology 2014, 468-470, 351-362. [CrossRef]

71. Amegadzie, B.Y.; Sisler, J.R.; Moss, B. Frame-shift mutations within the vaccinia virus A-type inclusion protein gene. Virology 1992, 186, 777-782. [CrossRef]

72. Randall, C.C.; Gafford, L.G.; Darlington, R.W.; Hyde, J. Composition of fowlpox virus and inclusion matrix. J. Bacteriol. 1964, 87, 939-944. [CrossRef]

73. Banville, M.; Dumas, F.; Trifiro, S.; Arif, B.; Richardson, C. The predicted amino acid sequence of the spheroidin protein from Amsacta moorei entomopoxvirus: Lack of homology between major occlusion body proteins of different poxviruses. J. Gen. Virol. 1992, 73, 559-566. [CrossRef] [PubMed]

74. Howard, A.R.; Weisberg, A.S.; Moss, B. Congregation of Orthopoxvirus Virions in Cytoplasmic A-Type Inclusions Is Mediated by Interactions of a Bridging Protein (A26p) with a Matrix Protein (ATIp) and a Virion Membrane-Associated Protein (A27p). J. Virol. 2010, 84, 7592-7602. [CrossRef] [PubMed]

75. McKelvey, T.A.; Andrews, S.C.; Miller, S.E.; Ray, C.A.; Pickup, D.J. Identification of the Orthopoxvirus p4c Gene, Which Encodes a Structural Protein That Directs Intracellular Mature Virus Particles into A-Type Inclusions. J. Virol. 2002, 76, 11216-11225. [CrossRef] [PubMed]

76. Ulaeto, D.; Grosenbach, D.; Hruby, D.E. The vaccinia virus 4c and A-type inclusion proteins are specific markers for the intracellular mature virus particle. J. Virol. 1996, 70, 3372-3377. [CrossRef]

77. Hansen, H.; Okeke, M.I.; Nilssen, Ø.; Traavik, T. Comparison and phylogenetic analysis of cowpox viruses isolated from cats and humans in Fennoscandia. Arch. Virol. 2009, 154, 1293-1302. [CrossRef] [PubMed]

78. Buller, R.M.; Palumbo, G.J. Poxvirus pathogenesis. Microbiol. Rev. 1991, 55, 80-122. [CrossRef] [PubMed]

79. Kastenmayer, R.J.; Maruri-Avidal, L.; Americo, J.L.; Earl, P.L.; Weisberg, A.S.; Moss, B. Elimination of A-type inclusion formation enhances cowpox virus replication in mice: Implications for orthopoxvirus evolution. Virology 2014, 452-453, 59-66. [CrossRef] 
80. Okeke, M.I.; Hansen, H.; Traavik, T. A naturally occurring cowpox virus with an ectromelia virus A-type inclusion protein gene displays atypical A-type inclusions. Infect. Genet. Evol. 2012, 12, 160-168. [CrossRef]

81. Bonhomme, F. Evolutionary Relationships in the Genus Mus. Curr. Top. Microbiol. Immunol. 1986, 127, 19-34. [CrossRef]

82. Buller, R.M.L.; Potter, M.; Wallace, G.D. Variable Resistance to Ectromelia (Mousepox) Virus Among Genera of Mus. Curr. Top. Microbiol. Immunol. 1986, 127, 319-322. [CrossRef]

83. Zheng, Z.-M.; Specter, S.; Zhang, J.-H.; Friedman, H.; Zhu, W.-P. Further characterization of the biological and pathogenic properties of erythromelalgia-related poxviruses. J. Gen. Virol. 1992, 73, 2011-2019. [CrossRef]

84. Suzuki, H.; Nunome, M.; Kinoshita, G.; Aplin, K.P.; Vogel, P.; Kryukov, A.P.; Jin, M.-L.; Han, S.-H.; Maryanto, I.; Tsuchiya, K.; et al. Evolutionary and dispersal history of Eurasian house mice Mus musculus clarified by more extensive geographic sampling of mitochondrial DNA. Heredity 2013, 111, 375-390. [CrossRef]

85. Kochan, G.; Escors, D.; González, J.M.; Casasnovas, J.M.; Esteban, M.; Escors-Murugarren, D. Membrane cell fusion activity of the vaccinia virus A17-A27 protein complex. Cell. Microbiol. 2007, 10, 149-164. [CrossRef] [PubMed]

86. Ohradanova, A.; Vullo, D.; Kopacek, J.; Temperini, C.; Betakova, T.; Pastorekova, S.; Pastorek, J.; Supuran, C.T. Reconstitution of carbonic anhydrase activity of the cell-surface-binding protein of vaccinia virus. Biochem. J. 2007, 407, 61-67. [CrossRef]

87. Maa, J.S.; Rodriguez, J.F.; Esteban, M. Structural and functional characterization of a cell surface binding protein of vaccinia virus. J. Biol. Chem. 1990, 265, 1569-1577. [CrossRef]

88. Laidlaw, S.M.; Skinner, M.A. Comparison of the genome sequence of FP9, an attenuated, tissue culture-adapted European strain of Fowlpox virus, with those of virulent American and European viruses. J. Gen. Virol. 2004, 85, 305-322. [CrossRef]

89. Meisinger-Henschel, C.; Schmidt, M.; Lukassen, S.; Linke, B.; Krause, L.; Konietzny, S.; Goesmann, A.; Howley, P.; Chaplin, P.; Suter, M.; et al. Genomic sequence of chorioallantois vaccinia virus Ankara, the ancestor of modified vaccinia virus Ankara. J. Gen. Virol. 2007, 88, 3249-3259. [CrossRef] [PubMed]

90. Blanié, S.; Mortier, J.; Delverdier, M.; Bertagnoli, S.; Camus-Bouclainville, C. M148R and M149R are two virulence factors for myxoma virus pathogenesis in the European rabbit. Vet. Res. 2009, 40, 14. [CrossRef]

91. Mossman, K.; Lee, S.F.; Barry, M.; Boshkov, L.; McFadden, G. Disruption of M-T5, a novel myxoma virus gene member of poxvirus host range superfamily, results in dramatic attenuation of myxomatosis in infected European rabbits. J. Virol. 1996, 70, 4394-4410. [CrossRef]

92. Kochneva, G.; Kolosova, I.; Maksyutova, T.; Ryabchikova, E.; Shchelkunov, S. Effects of deletions of kelch-like genes on cowpox virus biological properties. Arch. Virol. 2005, 150, 1857-1870. [CrossRef]

93. Tulman, E.R.; Afonso, C.L.; Lu, Z.; Zsak, L.; Sur, J.-H.; Sandybaev, N.T.; Kerembekova, U.Z.; Zaitsev, V.L.; Kutish, G.F.; Rock, D.L. The Genomes of Sheeppox and Goatpox Viruses. J. Virol. 2002, 76, 6054-6061. [CrossRef]

94. Kara, P.D.; Afonso, C.L.; Wallace, D.B.; Kutish, G.F.; Abolnik, C.; Lu, Z.; Vreede, F.; Taljaard, L.C.F.; Zsak, A.; Viljoen, G.J.; et al. Comparative sequence analysis of the South African vaccine strain and two virulent field isolates of Lumpy skin disease virus. Arch. Virol. 2003, 148, 1335-1356. [CrossRef]

95. Alejo, A.; Pontejo, S.M.; Alcami, A. Poxviral TNFRs: Properties and role in viral pathogenesis. In Advances in TNF Family Research; Springer: New York, NY, USA, 2011; Volume 691, pp. 203-210.

96. Hernaez, B.; Alonso-Lobo, J.M.; Montanuy, I.; Fischer, C.; Sauer, S.; Sigal, L.; Sevilla, N.; Alcamí, A. A virus-encoded type I interferon decoy receptor enables evasion of host immunity through cell-surface binding. Nat. Commun. 2018, 9, 1-14. [CrossRef]

97. Kluczyk, A.; Siemion, I.Z.; Szewczuk, Z.; Wieczorek, Z. The immunosuppressive activity of peptide fragments of vaccinia virus C10L protein and a hypothesis on the role of this protein in the viral invasion. Peptides 2002, 23, 823-834. [CrossRef]

98. Meyer, H.; Totmenin, A.; Gavrilova, E.; Shchelkunov, S. Variola and camelpox virus-specific sequences are part of a single large open reading frame identified in two German cowpox virus strains. Virus Res. 2005, 108, 39-43. [CrossRef]

99. Reynolds, S.E.; Earl, P.L.; Minai, M.; Moore, I.; Moss, B. A homolog of the variola virus B22 membrane protein contributes to ectromelia virus pathogenicity in the mouse footpad model. Virology 2017, 501, 107-114. [CrossRef]

100. Alzhanova, D.; Hammarlund, E.; Reed, J.; Meermeier, E.; Rawlings, S.; Ray, C.A.; Edwards, D.M.; Bimber, B.; Legasse, A.; Planer, S.; et al. T Cell Inactivation by Poxviral B22 Family Proteins Increases Viral Virulence. PLoS Pathog. 2014, 10, e1004123. [CrossRef]

101. McFadden, G. Poxvirus tropism. Nat. Rev. Genet. 2005, 3, 201-213. [CrossRef] 